\title{
Comparison of the Patient Safety Culture in the Nurses of Vasei Hospital in Sabzevar, Iran (2016-2020)
}

\author{
Shahrbanoo Talebi ${ }^{1}$, Ali Tajabadi ${ }^{2}$, Tahoura Afshari Saleh ${ }^{3}$, Rahele Arabasadi ${ }^{4}$
}

\begin{abstract}
Background \& Aims: One of the basic principles of health care is to maintain patient safety. Today, patient safety is a priority for any healthcare system that seeks to ensure and improve the quality of care. Being safe from dangers and injuries when receiving healthcare services is one of the most obvious and fundamental human rights. Despite advances in healthcare, patient safety, and patient-centeredness are still worrying issues around the world. According to the World Health Organization, tens of millions of people die or become disabled annually due to clinical errors or unsafe treatment processes, which is one of the five leading causes of death in the world. Recent reports also show that approximately, $13.5 \%$ of hospitalized patients experience at least one adverse event during their hospitalization each year, $44 \%$ of which is preventable. The biggest challenge to make the healthcare system safer is changing the culture. Assessing the patient safety culture can provide information on how structures and processes within the system affect patient outcomes. However, the question remains that, given the structure of the existing healthcare system and the fact that in recent years, patient safety has been at the forefront of accreditation of medical centers, has the safety culture been able to find and establish its place in these centers and has the staff of medical centers (especially nurses) paid attention to patient safety culture due to the changes that have taken place in the past years. Therefore, this study was conducted to compare patient safety culture in nurses of Sabzevar Vasei Hospital between 2016 and 2020.

Materials \& Methods: The present study is a descriptive-analytical cross-sectional study that was conducted between 2016 and 2020. 123 nurses of Vasei Hospital were selected in 2016 and 124 were selected in 2020 via convenience sampling. Inclusion criteria were having at least 6 months of work experience and consent to participate in the present study, applied in both 2016 and 2020. A two-part questionnaire was used to collect data. In the first part, the demographic information of the samples including age, gender, field and degree, occupation, type of employment, work experience in the hospital, work experience in the recent ward, working hours per week were examined. The second part of the questionnaire included the Persian version of the "Patient Safety Culture Survey" (HSOPSC). The questionnaire was designed by American Agency for Healthcare Research and Quality in 2004. In the present study, the questionnaire was given to 10 experts to confirm the validity, and their opinions were applied. The reliability of the questionnaire was investigated in 2016 using Cronbach's alpha coefficient which was between $0.74-0.81$ for safety culture and its various dimensions. This questionnaire has 42 questions designed on a 5-point Likert scale ranging from strongly disagree to strongly agree. Therefore, each question was assigned a score of 1 to 5. This questionnaire has 12 dimensions including the frequency of reporting events, the overall perception of safety, managerial expectations and actions, organizational learning, teamwork within the organization, open communication channels, communication and feedback, non-punitive response to errors, staff-related work issues, safety management support, teamwork out of the organization, transmission and exchange of information. In this study, after calculating the percentage of positive responses in each dimension (sum of completely agree and disagree options), and based on the questionnaire guide and examining the 12 dimensions, an average positive response of at least 70 indicated optimal safety culture, between 50-69 showed a moderate level of safety culture, and below 50 indicated a low
\end{abstract}

\footnotetext{
1. Ms in Nursing, Clinical Research Center of Sabzevar Vasei Hospital, Sabzevar University of Medical Sciences, Sabzevar, Iran

2. Department of Emergency Medicine, School of Paramedical Sciences, Sabzevar University of Medical Sciences, Sabzevar, Iran

3. Department of Emergency Medicine, School of Medicine, Sabzevar University of Medical Sciences, Sabzevar, Iran ${ }^{4}$. BS in Nursing, Clinical Research Center of Sabzevar Vasei Hospital, Sabzevar University of Medical Sciences, Sabzevar, Iran (Corresponding author) Tel: 09151738309 Email: rarabasadi@gmail.com
} 
level of safety culture. Data analysis was performed using descriptive statistics, chi-square, Fisher's exact test, and independent t-test in SPSS version 16, and the significance level was set at $\mathrm{P}<0.05$.

Results: The obtained results regarding the individual characteristics of the study units showed most subjects were women and married. There was no significant difference in terms of demographic characteristics of nurses in 2016 and $2020(\mathrm{P}>0.05)$. The overall score of patient safety culture in 2016 was $41.9 \pm 6.9 \%$ which was low, also the overall score of patient safety culture in 2020 was $51.2 \pm 7.7 \%$ which was moderate. In 2016, expectations and managerial actions had the highest score $(63.1 \pm 29.3 \%)$ and non-punitive response to errors had the lowest score $(11.3 \pm 15.6 \%)$. In 2020, the dimensions of communication and feedback and non-punitive response to errors had the highest scores $(70.6 \pm 23.4 \%$ and $31.8 \pm 24.3 \%$ respectively) among the various dimensions of patient safety culture. The comparison of the mean scores of some dimensions in 2016 and 2020 was also statistically significant $(\mathrm{P}<0.001)$. The results showed better performance of some dimensions such as the frequency of reporting, open communication channels, communication and feedback, non-punitive response to errors, staff-related work issues, and transmission and exchange of information in 2020 compared to the initial survey in 2016. Regarding the dimensions of organizational learning and teamwork within the organization, the average score was higher in 2016, which was also statistically significant. Comparison of mean changes in other dimensions of the overall perception of safety, management expectations and actions, safety management support, and teamwork outside the organization in 2016 and 2020 were not statistically significant (P>0.05). In 2016, 61\% of nursing staff made no errors, which was equal to $47.6 \%$ in 2020 and is not statistically significant. Also in 2016, $12.2 \%$ of patients reported the safety of the ward to be very good or excellent, which was $26.6 \%$ in 2020 , and is statistically significant $(\mathrm{P}<0.05)$.

Conclusion: The findings of the study indicate that while there are significant improvements in the overall score of safety culture and some of its dimensions, there are still dimensions of patient safety culture that managers and officials should strive to improve and strengthen. In this regard, general strategies for further improvement of patient safety practices and more investment in determinants of patient safety culture, especially in the areas of organizational learning and teamwork within the organization, should be guided and informed. Also, regular management and assessment of patient safety can enable hospitals to better understand and perform more efficiently.

Keywords: Patient Safety, Culture, Nurses

\section{Conflict of Interest: No}

How to Cite: Talebi SH, Tajabadi A, Afshari Saleh T, Arabasadi R. Comparison of the Patient Safety Culture in the Nurses of Vasei Hospital in Sabzevar, Iran (2016- 2020). Iran Journal of Nursing. 2021; 34(130):1-14.

Received: 2 March 2021

Accepted: 2 Jun 2021 


\title{
مقايسهى فرهنك ايمنى بيمار در يرستار ان بيمار ستان واسعى سبزوار بين سالهاى هوبا و IrqA
}

\author{
شهربانو طالبى'، على تاج آبادى '، طهورا افثارى صالح"، راحله عرب اسدىع
}

زمينه و هدف: يكى از اصول مراقبت سلامت، حفظ ايمنى بيمار مىباشد. ارزيابى فرهنگ ايمنى بيمار مى تواند اطلاعاتى در مورد جخحونخى تأثير

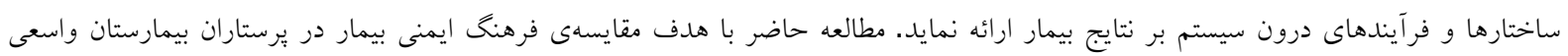

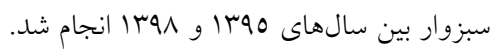

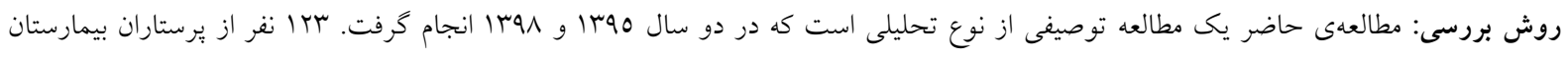

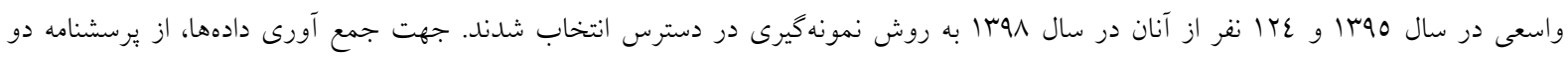

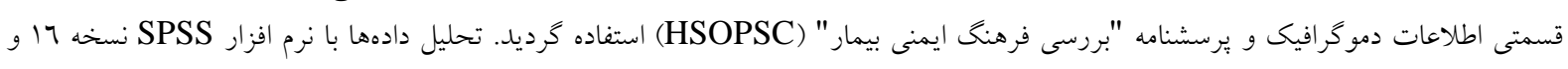

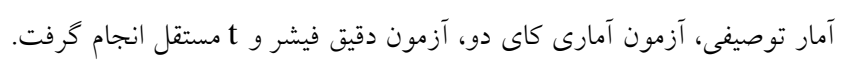

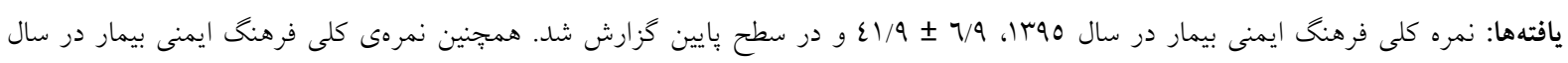

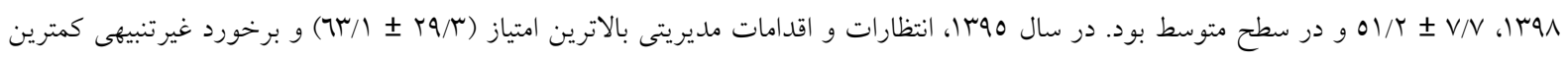

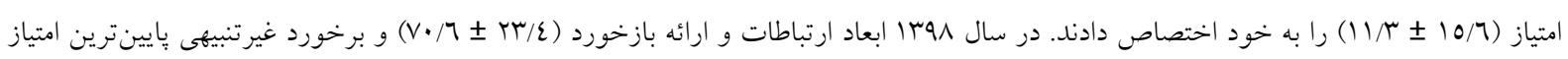

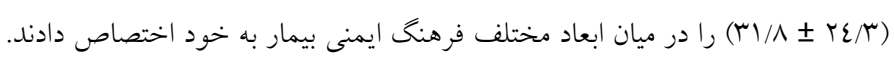

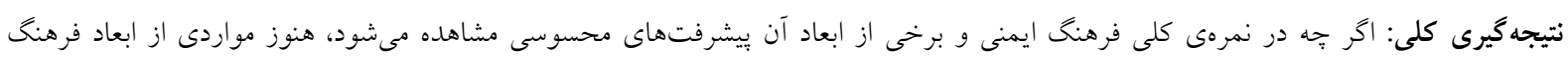

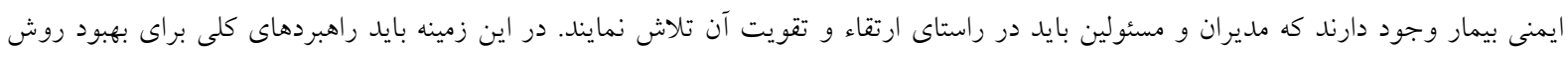

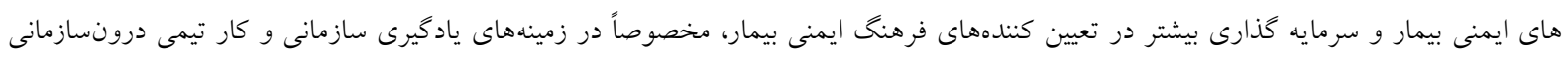
راهنمايى و اطلاع رسانى شود.

\author{
كليد وازهها: ايمنى بيمار، فرهنگ، يرستاران \\ تعارض منافع: وجود ندارد. \\ تاريخ دريافت: T9/I T/M

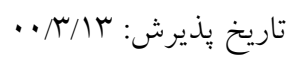

\footnotetext{
' ' كارشناس ارشد يرستارى، مركز تحقيقات بالينى بيمارستان واسعى سبزوار، دانشكاه علوم يزشكى سبز سبزوار، سبزوار، ايران

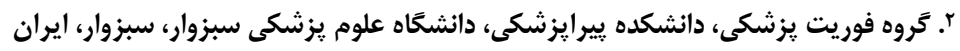

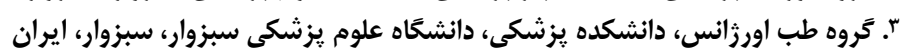

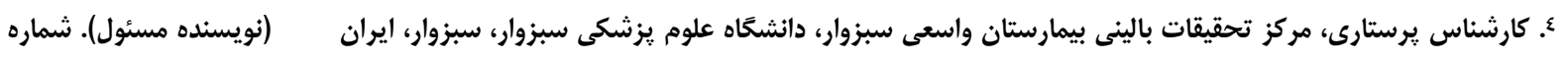




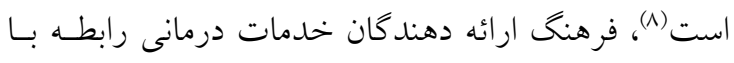

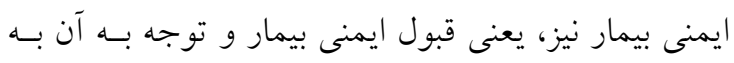

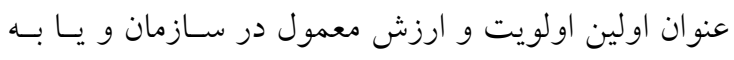

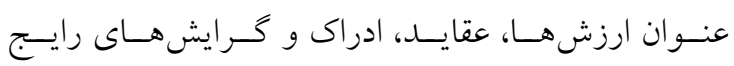

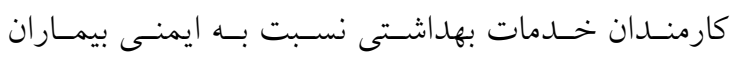

توصيف مى گردد كه در رفتار آنها متجلى مىشود (9).

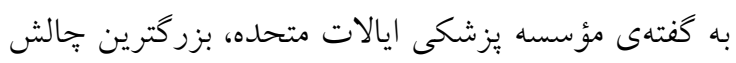

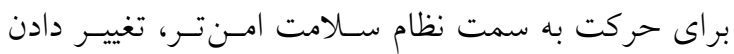

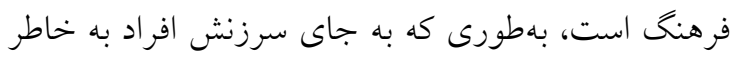

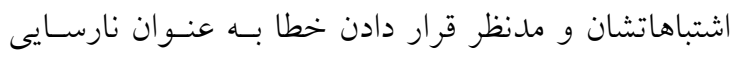

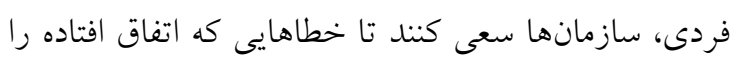
مورد بررسى قرار دهند. در نتيجهى اين رويكرد، فرصـت فستاف

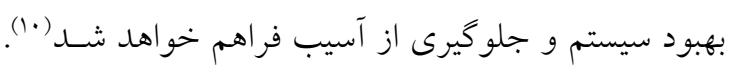

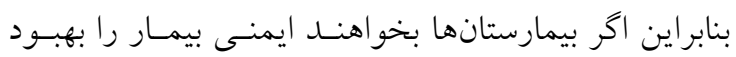

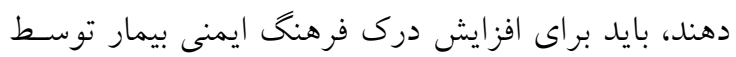

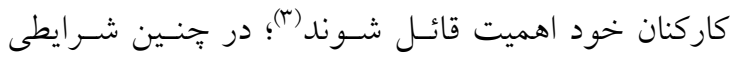

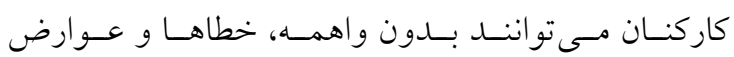
ناخواسته را كزارش و فرصت يادگيرى از اشتباهات خــود

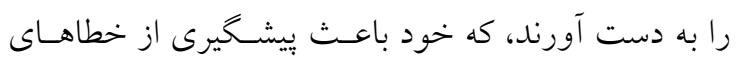
سيستماتيك و افزايش ايمنى بيمار مىشود (1).

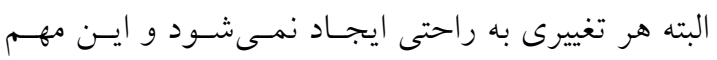

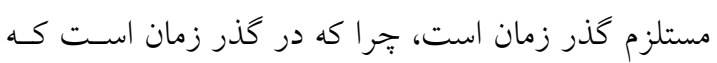

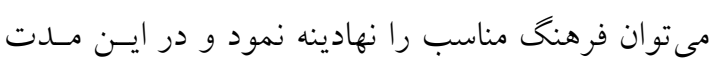

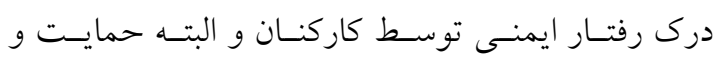

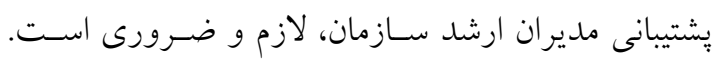

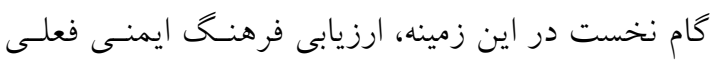

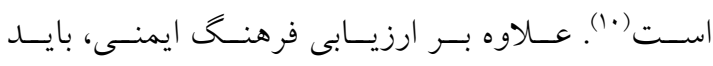

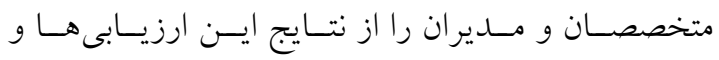

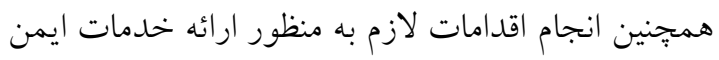
به بيماران، حفظ شرايط مطلوب و ارتقاء شرايط نيازمنـد مداخله، مطلع ساخت (11). مطالعات مختلف جهت سنجش فرهنگ ايمنى انجام شده است و نتايج آن نشان مىدهد كه فرهنگ ايمنسى بيمـاران

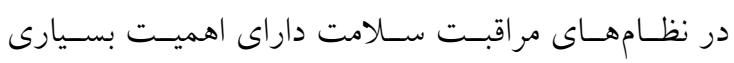

\section{مقدمه}

مراقبت همه جانبه يكى از اركان اصلى در زمينه خــدمات

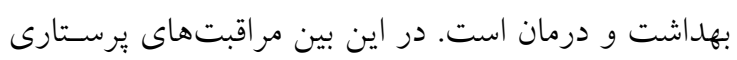

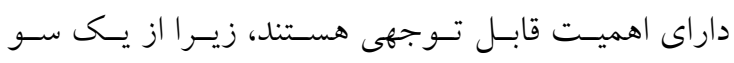

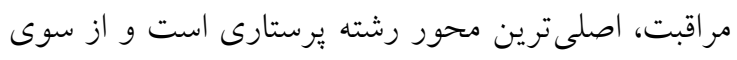

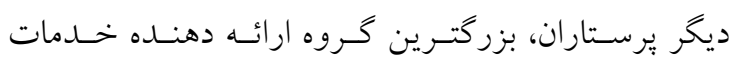
بهداشتى را تشكيل مىدهند و در تداوم مراقبت، ارتقــاء و

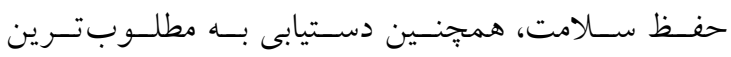

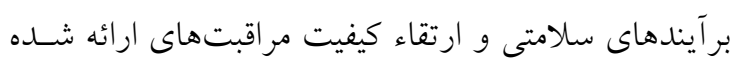

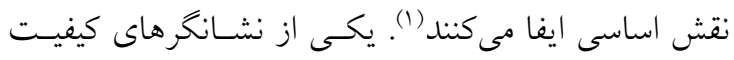

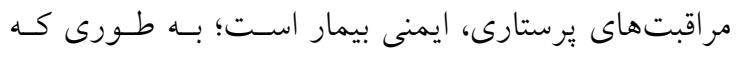

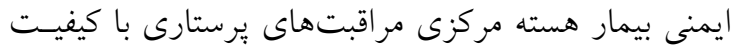

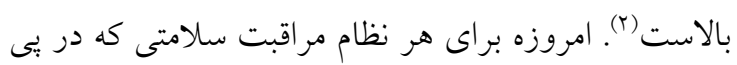

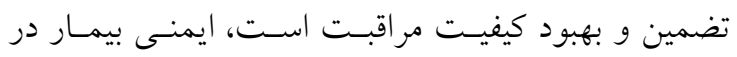

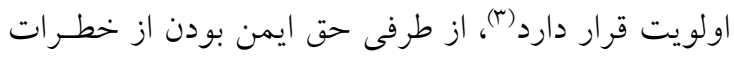

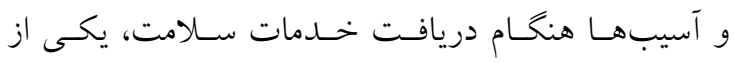

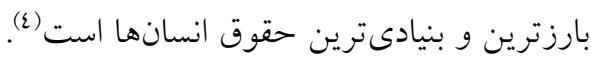

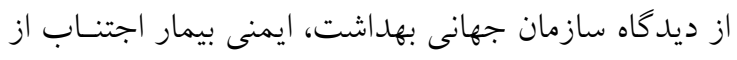

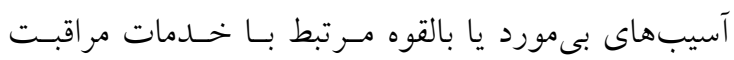

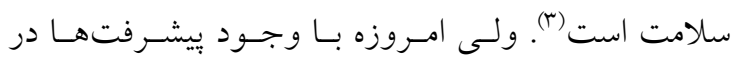

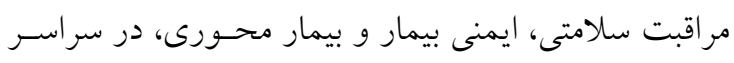

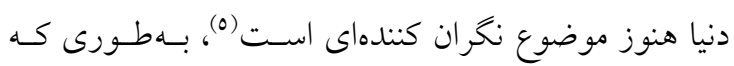

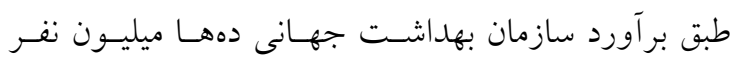

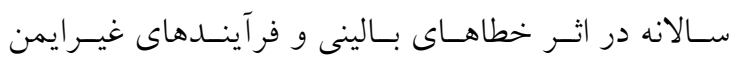

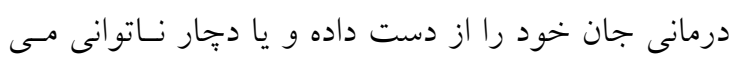

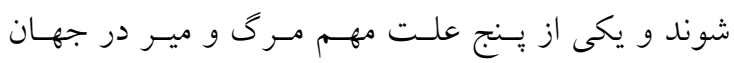

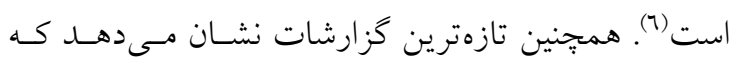

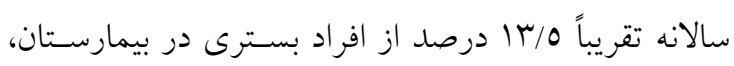

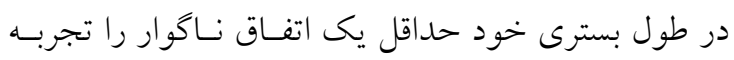

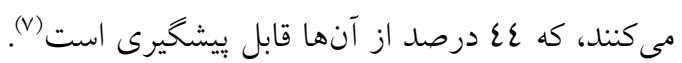
تلاش براى بهبود وضعيت ايمنى بيمـاران يكسى از اعمـال

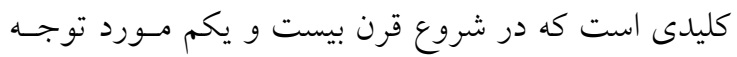

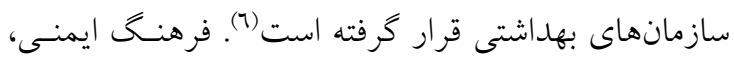
يكى از عوامل اصلى تعيين كنتـــه ميـزان ايمنسى سـازمان 
مخدوش و يا ناقص بودن برسشنامهها بود كـه يرسشـنامه

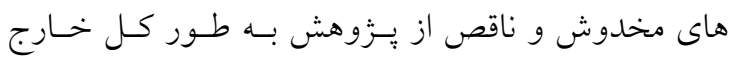

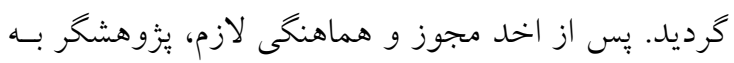

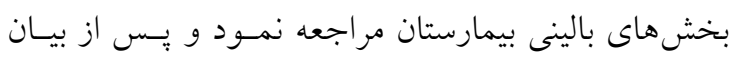

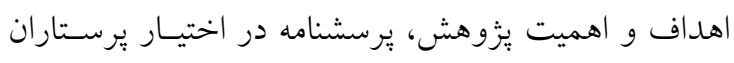

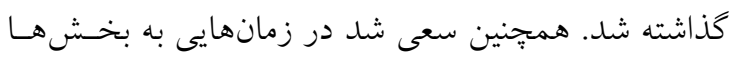

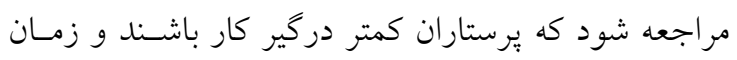

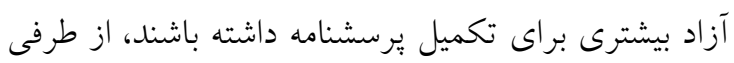

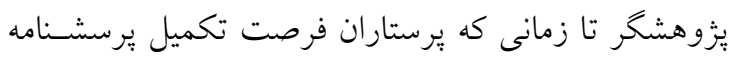

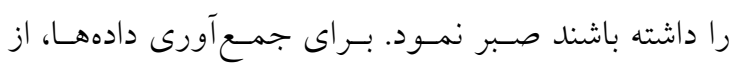

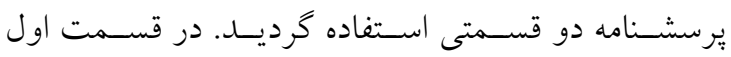

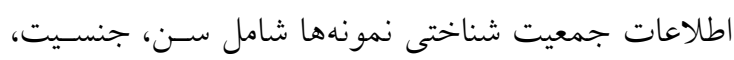
رشته و مقطع تحصيلى، رسته شغلى، نوع استخدام، سـابقه

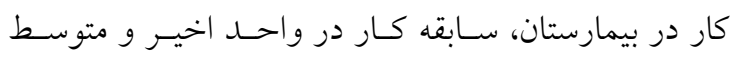
ساعت كار در هفته مورد بررسى قرار كرفت. قسمت دوم

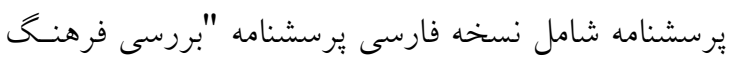
ايمنى بيمار"Hospital Survey on Patient Safety Culture (HSOPSC)

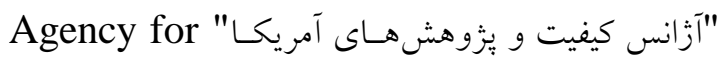
در Health Research and Quality (AHRQ)

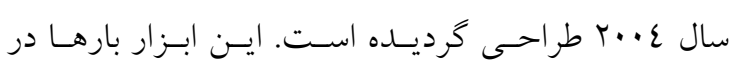

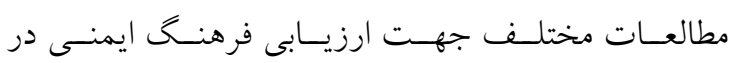

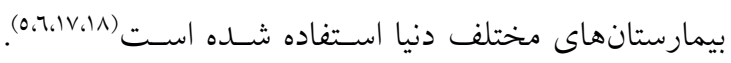

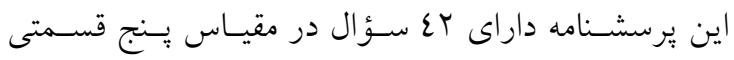

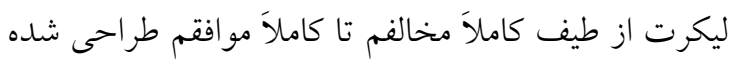

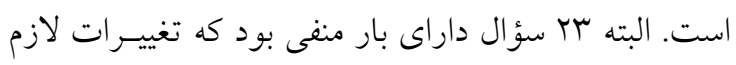

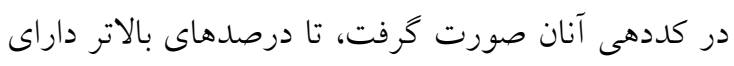
وضعيت مطلوبتر باشد. بنابراين هر يك از سؤالات نمره

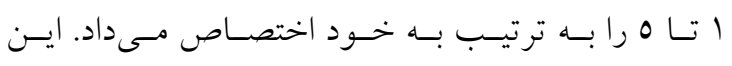

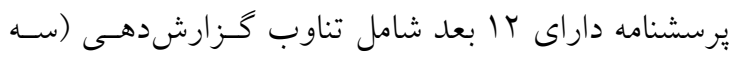

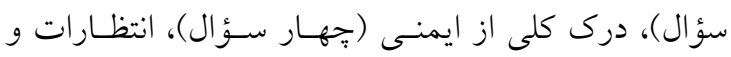

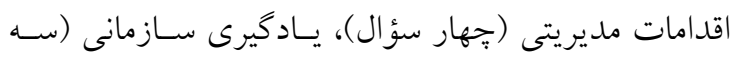

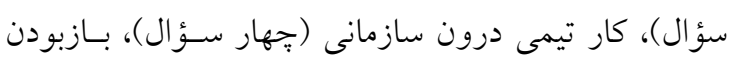

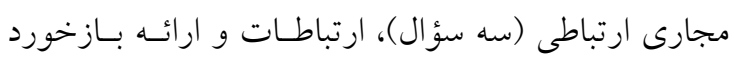

است(10-1)، در اين بين برستاران در خط مقدم مراقبت از

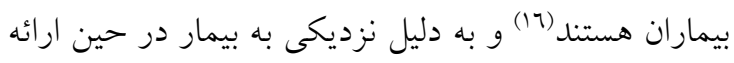

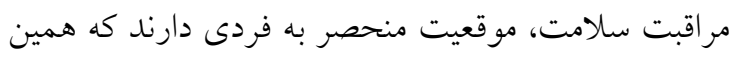

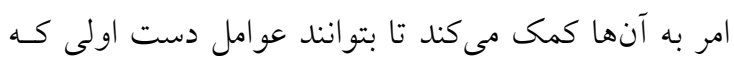

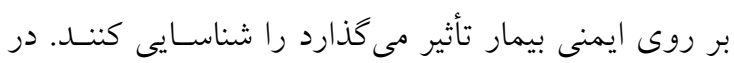

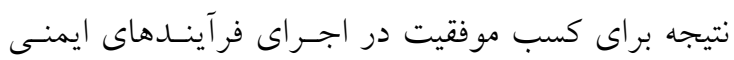

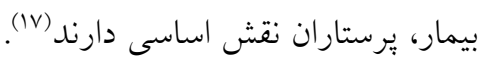

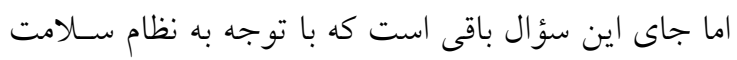

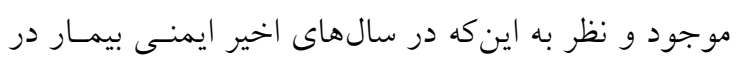

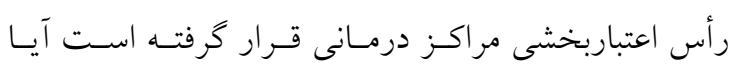

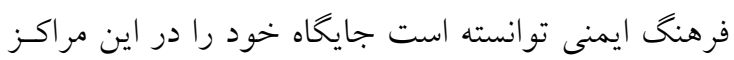

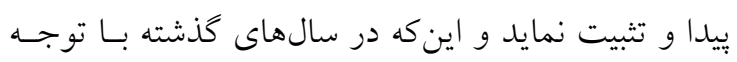

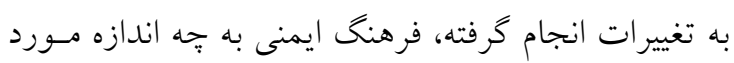

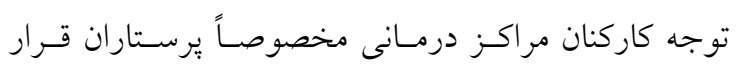

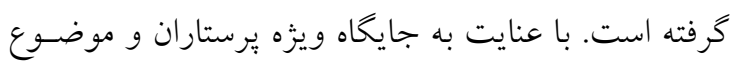

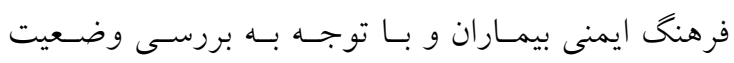

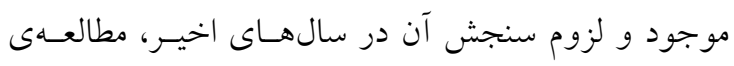

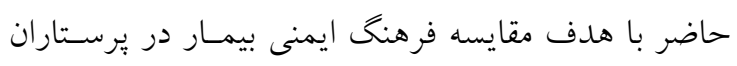

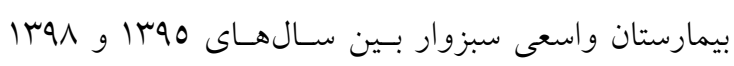

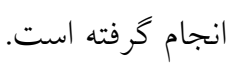

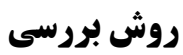

مطالعهى حاضر يكى مطالعه توصيفى تحليلى اسـت كـه

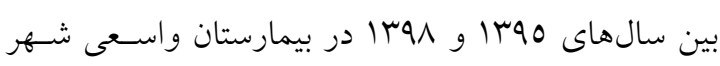

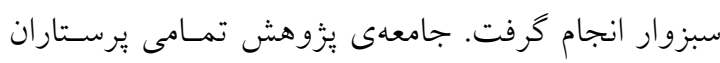
شاغل در بخشهاى بالينى بيمارستان (10 ن نفــ در سـال

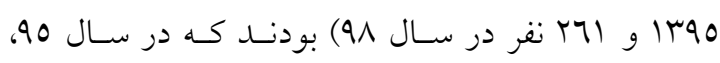

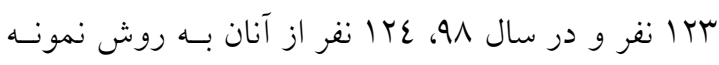

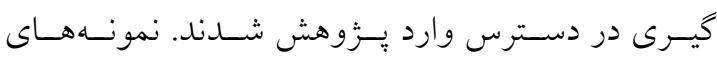

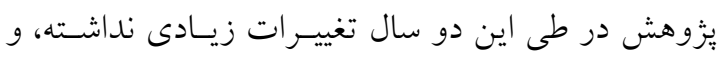

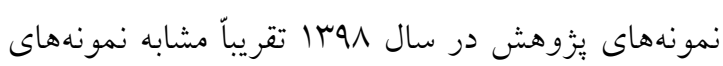

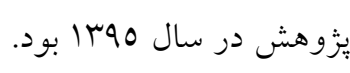

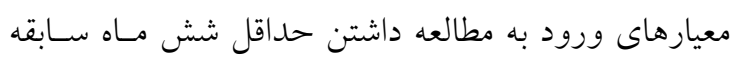

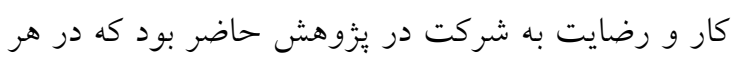

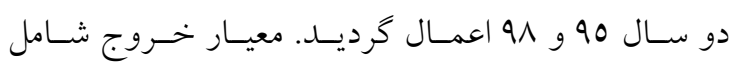


مشــاركت كنـــــان و وضـعيت فرهنـع ايمنسى در ابعـاد

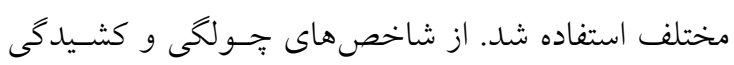

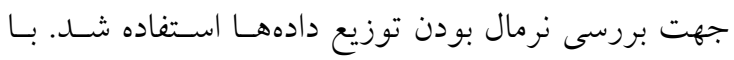

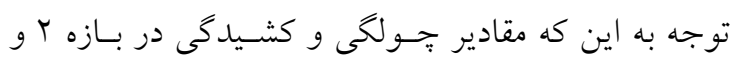
r- مىباشد، جهت بررسى مقايسه متغيرهاى كمى بين دو

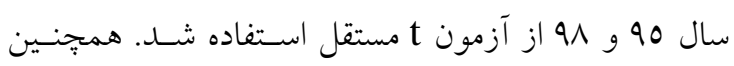
جهت مقايسه متغيرهاى اسمى بين دو سال از آزمون كـاى دو و دقيق فيشر استفاده كرديد. سطح معنى دارى كمتـر از

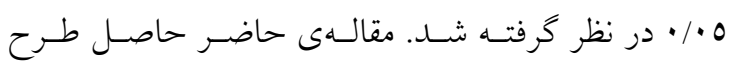

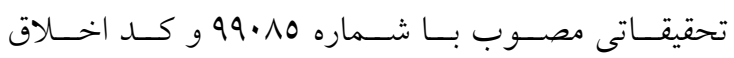
IR.MEDSAB.REC.1399.081 اخلاق دانشخاه علوم يزشكى سبزوار است.

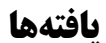

نتايج بـه دسـت آمـده در رابطـه بـا ويزّكى هــاى فـردى

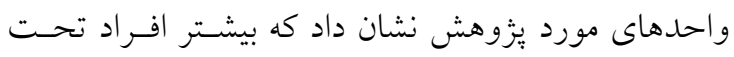
مطالعه زن و متأهل بودند. تفاوت معنىدارى از نظر سـاير مشخصـات جمعيـت شـناختى در برستاران در دو سـال

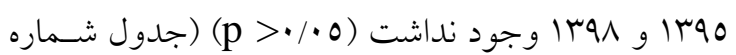
1). ميانخين و انحراف معيار سن در بين شـركت كنتـدكان

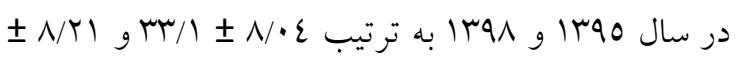
كآ

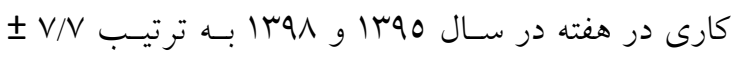
آ آزمون t مستقل تفاوت معنى دارى از نظر سن (

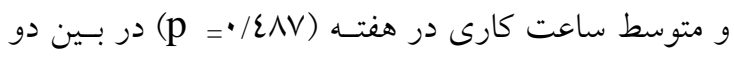

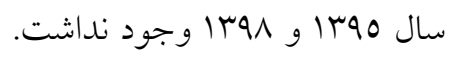

(سـه سـؤال)، برخــورد غير تنبيهـى (سـهـ سـؤال)، مســائل

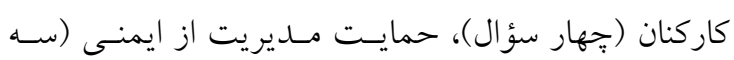

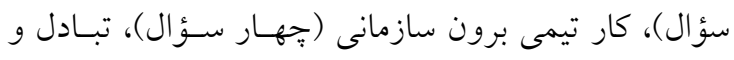

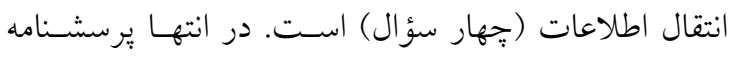

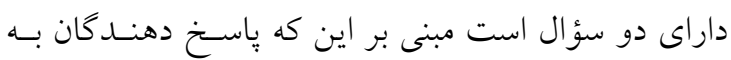

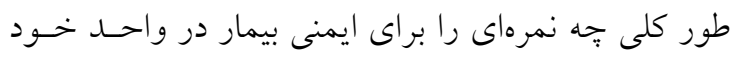

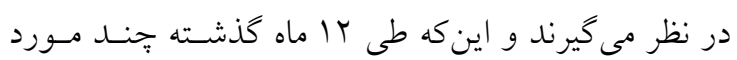

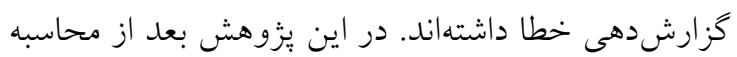

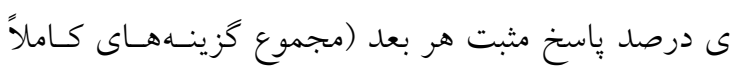

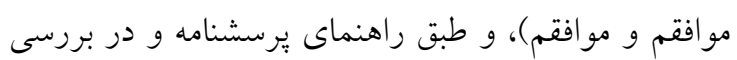

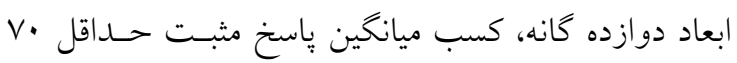
نشان دهندهى سطح فرهنگ ايمنى مطلوب، بين ل0 تا بـ 79

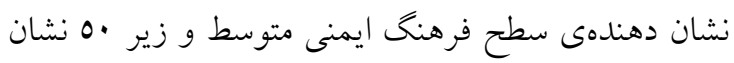
دهندهى سطح فرهنگ ايمنى هايين در نظر گرفته شد.

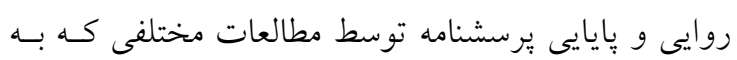

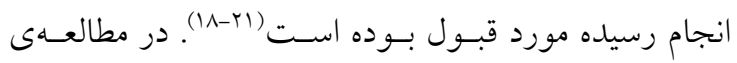

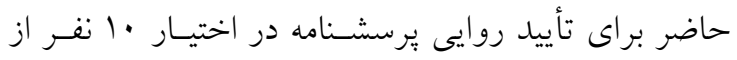

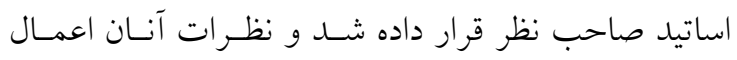

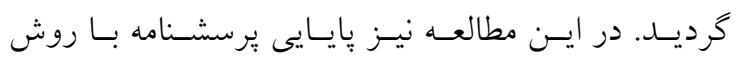

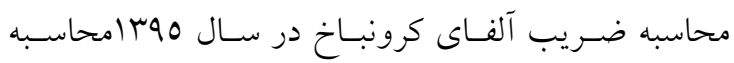

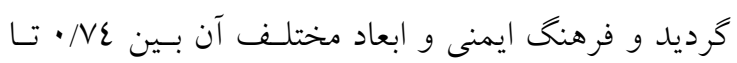

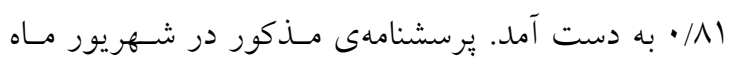

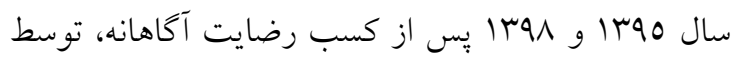

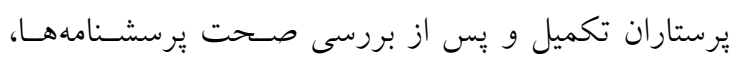

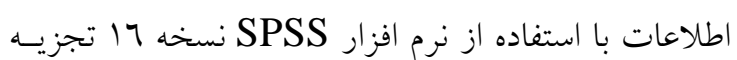

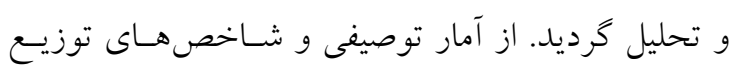

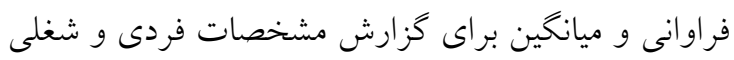

جدول شماره (: توزيع فراوانى واحدهاى مورد يزوهش بر حسب متغيرهاى جمعيت شناختى

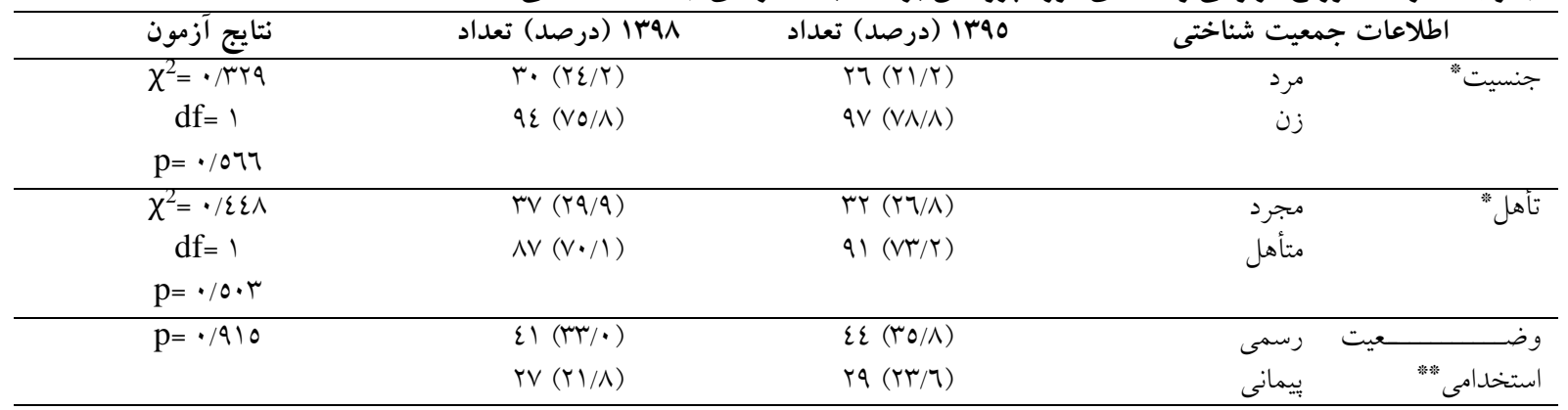




\begin{tabular}{|c|c|c|c|c|}
\hline & $\varepsilon(\Gamma / \Gamma)$ & $\varepsilon(\Gamma / \Gamma)$ & قراردادى & \\
\hline & $17(1 Y / 9)$ & IV $(I \Gamma / \Lambda)$ & شركتى & \\
\hline & $r(r q / 1)$ & $r q(Y Y / O)$ & طرحى & \\
\hline$\chi^{2}=7 / 9 \vee 0$ & $10(1 Y / 1)$ & $1 \cdot(\Lambda / 1)$ & 7 ماه تا ا سال & سابقه كار"، سال \\
\hline $\mathrm{df}=0$ & $19(10 / \pi)$ & $Y T(Y \backslash / Y)$ & $r-0$ & \\
\hline \multirow[t]{4}{*}{$\mathrm{p}=\cdot / r T r$} & $\varepsilon \cdot(r Y / \Gamma)$ & $r q(Y T / T)$ & $7-1$. & \\
\hline & $1 \wedge(1 \varepsilon / 0)$ & $r \varepsilon(19 / 0)$ & $11-10$ & \\
\hline & $19(10 / 4)$ & $r T(Y I / T)$ & $17-r$. & \\
\hline & $\| r(1 \cdot / 0)$ & $\wedge(7 / 0)$ & $\geq Y I$ & \\
\hline \multirow[t]{3}{*}{$\mathrm{p}=\cdot / 2 q 1$} & $I V(I r / V)$ & $\pi(9 / V)$ & ثابت صبح & نوع نوبت كارى"*" \\
\hline & $0(\Sigma / \cdot)$ & $r(T / \varepsilon)$ & ثابت عصر & \\
\hline & $1 \cdot r(\Lambda T / r)$ & $1 \cdot \Lambda(\Lambda V / \Lambda)$ & در كردش & \\
\hline
\end{tabular}

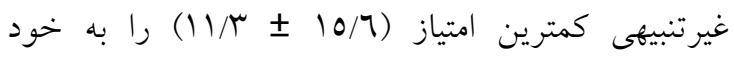
اختصاص دادند. در سال ^هץ| ابعاد ارتباطات و ارائه

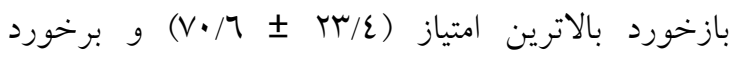

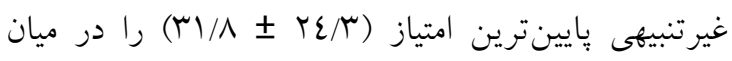
ابعاد مختلف فرهنخ ايمنى بيمار به خود اختصاص دادند

$$
\text { (جدول شماره ( ) (ج). }
$$

بر حسب درصد پِاسخهاى مثبت، نمرهى كلى فرهنگ

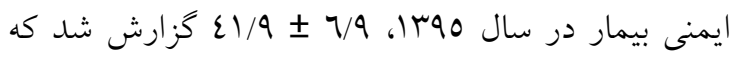
در سطح پايين است، همجنين نمرهى كلى فرهنگ ايمنى بيمار در سال 19 1/، V/V I/ I و در سطح متوسط بود كه نسبت به سال 90ب1 افزايش معنىدارى داشت

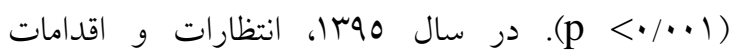

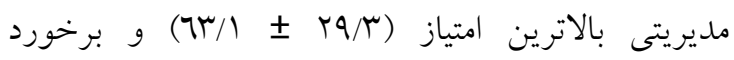

جدول شماره ץ: مقايسه ميانكين و انحراف استاندارد درصد ياسخهاى مثبت در ابعاد دوازده كَانه فرهنَ ايمنى بيمار در يرستاران بين

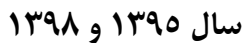

\begin{tabular}{|c|c|c|c|}
\hline نتايج آزمون t مستقل & ميانگين و انحر اف استاندارد درصد & 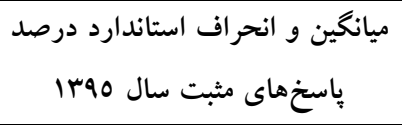 & ابعاد دوازده گانه فرهنگ ايمنى \\
\hline $\mathrm{p}=<\cdot / \cdots) \mathrm{df}=r \varepsilon 0 \mathrm{t}=-V / r \Lambda$ & $0 \varepsilon / 1 \pm r o / r$ & MI/O \pm ro/r & تناوب گزارش دهى \\
\hline $\mathrm{p}=\cdot / 07 \cdot \mathrm{df}=r \varepsilon \varepsilon / \mathrm{VV} \cdot \mathrm{t}=-\cdot / 0 \mathrm{NV}$ & $\varepsilon \Lambda / r \pm r \cdot / \Lambda$ & $\varepsilon r / 0 \pm r q / \Lambda$ & درى كلى از ايمنى \\
\hline $\mathrm{p}=\cdot / \varepsilon 0 \cdot \mathrm{df}=r\{0 \mathrm{t}=\cdot /$ / 0$\rceil$ & $09 / 7 \pm r \cdot / 1$ & $\tau r / 1 \pm r q / r$ & انتظارات و اقدامات مديريتى \\
\hline $\mathrm{p}=<\cdot / \cdots+\mathrm{df}=r \mu \mathrm{r} / q \cdot 1 \quad \mathrm{t}=0 / 109$ & $\varepsilon r / \Gamma \pm \mu r / r$ & $T r / 9 \pm r V / 0$ & ياد ميرى سازمانى \\
\hline $\mathrm{p}=\langle\cdot / \cdots|\mathrm{df}=r| r / v \cdot V \mathrm{t}=\mathrm{T} / \wedge 07$ & $r / / \Lambda \pm r \cdot / \tau$ & $7 \cdot / 9 \pm r q / 1$ & كار تيمى درون سازمانى \\
\hline $\mathrm{p}=<\cdot / \cdots) \mathrm{df}=r \varepsilon 1 / V r \cdot \mathrm{t}=-r / V \cdot \cdot$ & $\varepsilon q / \varepsilon \pm r r / r$ & $\varepsilon \cdot / 9 \pm 19 / \varepsilon$ & بازبودن مجارى ارتباطى \\
\hline $\mathrm{p}=<\cdot / \cdot \cdot \mathrm{df}=r \varepsilon 0 \mathrm{t}=-11 / \wedge \cdot 0$ & $V \cdot / \neg \pm r r / \varepsilon$ & $\mathrm{r} / \cdot \pm r_{0 / q}$ & ارتباطات و ارائه بازخورد \\
\hline $\mathrm{p}=<\cdot / \cdots+\mathrm{df}=r \| / / 0 \varepsilon r \quad \mathrm{t}=-V / 9 \vee \wedge$ & $r 1 / \Lambda \pm r \varepsilon / r$ & $11 / \pi \pm 10 / 7$ & برخورد غيرتنبيهى \\
\hline $\mathrm{p}=<\cdot / \cdot \cdot \mathrm{df}=r \mu \neg / \mu \Lambda \Lambda \mathrm{t}=-1 T / \neg r\rceil$ & $20 / 9 \pm 19 / 9$ & $17 / 9 \pm 17 / r$ & مسائل كاركنان \\
\hline $\mathrm{p}=\cdot / r \mathrm{r} V \mathrm{df}=r \varepsilon 0 \mathrm{t}=-\cdot / 9 \wedge r$ & $0 \varepsilon / 1 \pm r o / 0$ & $0 . / 9 \pm T V / V$ & حمايت مديريت از ايمنى \\
\hline $\mathrm{p}=\cdot / r 0 \cdot \mathrm{df}=r \varepsilon 0 \mathrm{t}=-\cdot / 9 \mu \mathrm{r}$ & $O V / \neg \pm r T / V$ & $0 \varepsilon / \Gamma \pm r r / r$ & كار تيمى برون سازمانى \\
\hline $\mathrm{p}=\langle\cdot / \cdot \cdot| \mathrm{df}=r \varepsilon 0 \mathrm{t}=-1 \cdot / r \cdot v$ & $\pi r / r \pm r \varepsilon / r$ & $r \cdot / \neg \pm r \varepsilon / \Lambda$ & تبادل و انتقال اطلاعات \\
\hline 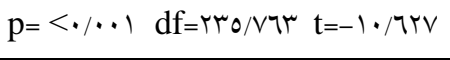 & $01 / \tau \pm V / V$ & $\sum 1 / 9 \pm 7 / 9$ & نمره كلى فرهنگ ايمنى بيمار \\
\hline
\end{tabular}


مديريت از ايمنى و كار تيمى برون سازمانى در سال

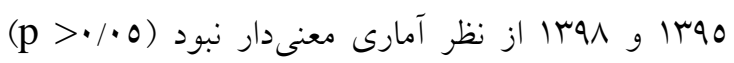

$$
\text { (جدول شماره ( ) }
$$

در سـال 90با، ال7 درصـــ از كاركنـان يرسـتارى هـيج

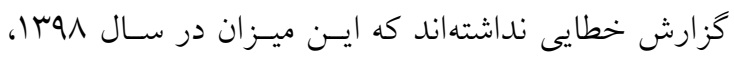

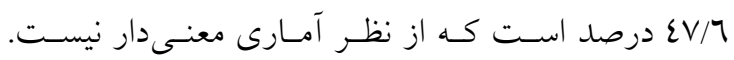

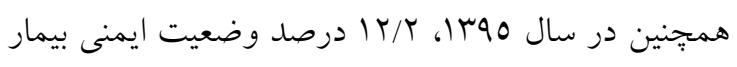
واحد خود را بسيار خوب يا عالى كزارش كردند كه ايسن

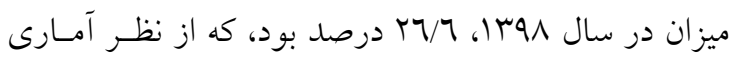

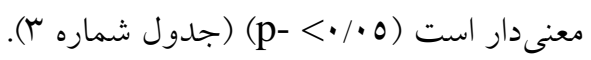

مقايسه ميانگين نمرات بر حسب درصد بِاسخهاى مثبت

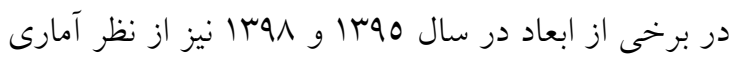

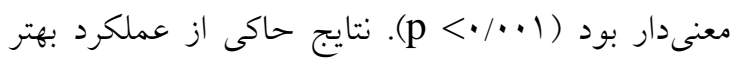

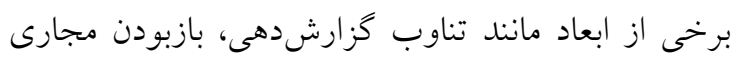

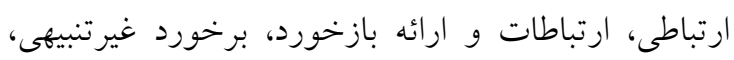

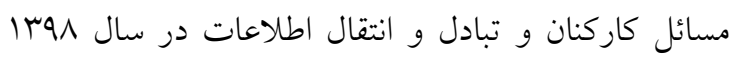
در مقايسه با بررسى اوليه در سال 901ا بوده. در رابطه با بال

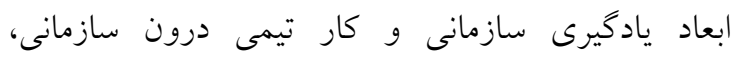

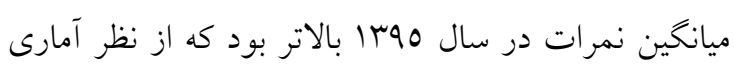

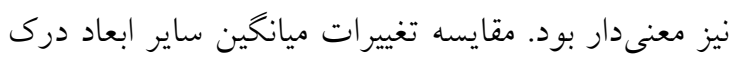

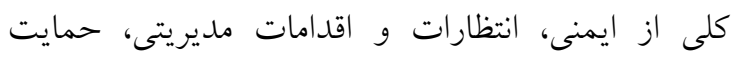

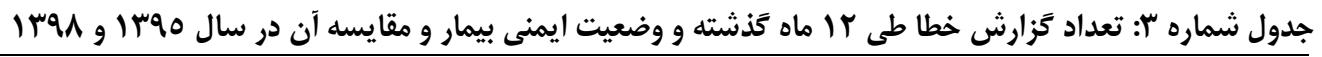

\begin{tabular}{|c|c|c|c|c|}
\hline p-value & 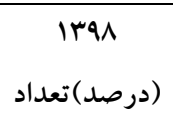 & 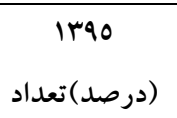 & وضعيت & متغير \\
\hline \multirow[t]{6}{*}{$\cdot / T / \varepsilon$} & $09\left(\sum V / 7\right)$ & Vo $(71 / \cdot)$ & صفر & \\
\hline & $\varepsilon r(r \varepsilon N)$ & $r \Lambda(Y Y / \Lambda)$ & $1-r$ & \\
\hline & $1 r(1 \cdot / 0)$ & $9(V / r)$ & $r-0$ & كزارش خطا" \\
\hline & $\varepsilon(r / T)$ & $V(O N)$ & $7-1$. & \\
\hline & $r(T / \varepsilon)$ & $r(1 / 7)$ & $11-r$. & \\
\hline & $r(1 / 7)$ & $r(1 / 7)$ & •r بو بيشتر & \\
\hline \multirow[t]{5}{*}{$\% / \cdots 7$} & $\wedge(7 / \varepsilon)$ & $V(O / N)$ & بسيار ضعيف & \\
\hline & $\varepsilon \cdot(r T / \Gamma)$ & $\Pi(Y T / \Lambda)$ & ضعيف & وضعيت ايمنى به طور \\
\hline & $\varepsilon r(r \varepsilon N)$ & $\eta(00 / r)$ & قابل قبول & كلى" \\
\hline & $Y \wedge(Y Y / T)$ & $11(1 / 9)$ & بسيار خوب & \\
\hline & $0(\Sigma / \cdot)$ & $\varepsilon(\Gamma / \mu)$ & 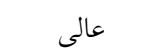 & \\
\hline
\end{tabular}

فقط تعلداد كمى از كاركنان يرستارى در كا ماه كذشـتهى

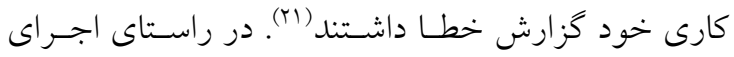

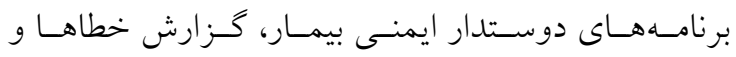

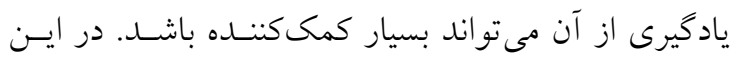

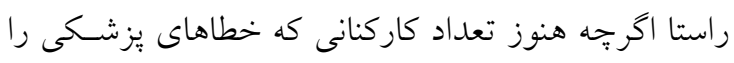

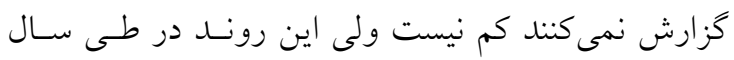

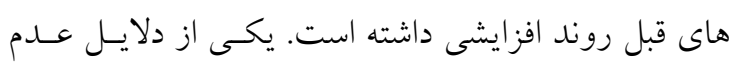

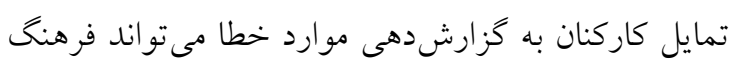

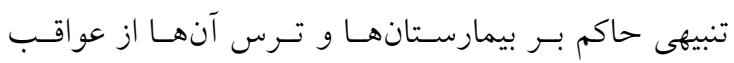

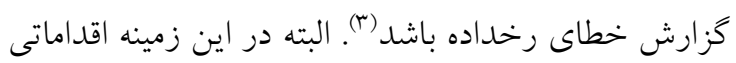

\section{بحث و نتيجه كيرى} از آنجا كه يرستاران نقش كليدى درئرى ارتقاى فرهنخ ايمنى

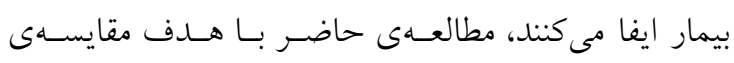

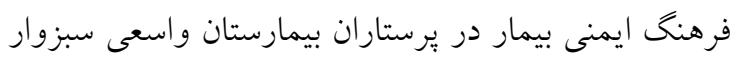

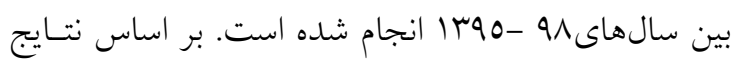

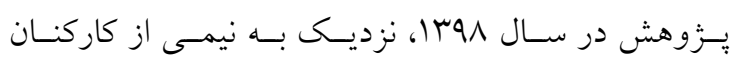

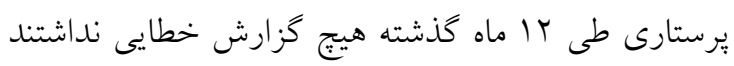

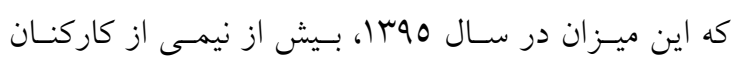

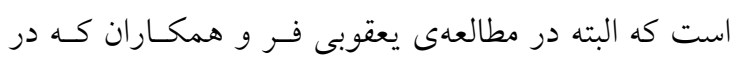

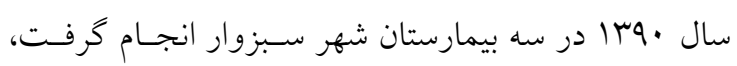


نمودهاند. در مطالعات مختلف در ايسران ميـانخين سـطوح

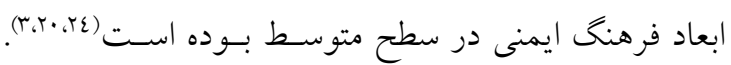

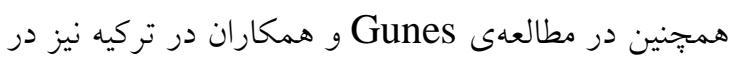
سطح متوسط كزارش شده است (Tr). در رابطه با تغييرات ابعاد فرهنـع ايمنسى بيمـار در سـال

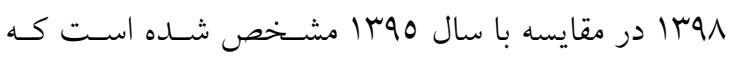
بيشتر ابعاد تغييرات معنىدار مثبتى داشتهانـــ. ولـى در دو بعد ياد گيرى سازمانى و كار تيمى درون سازمانى تغييرات

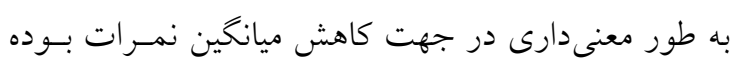

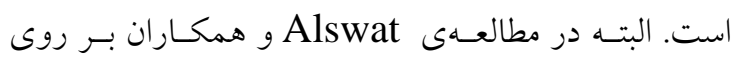

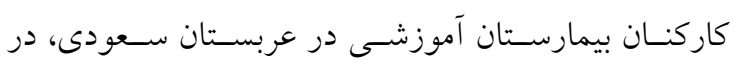

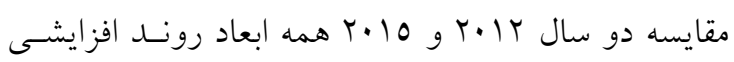
داشته است (T0)، كه با مطالعهى حاضر همخوانى ندارد.

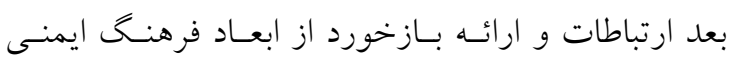
بيمار، به معناى اين است كه به تغييرات صورت كرفته بـر اساس گـزارش حـوادث ناخواسـته بـازخورد نشـان داده

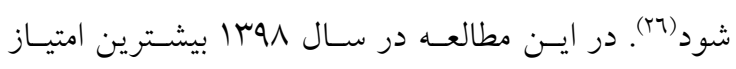
مربوط به ابعاد ايمنى بيمار است و در سطح مطلوب قـرار

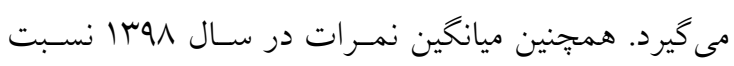

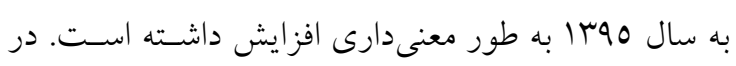

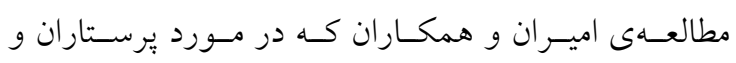
يزشكان شاغل در مركز درمانى منتخب ارتـش جمهـورى اسلامى انجام شد، نيز بيشترين ميانخين مربوط به اين بعد

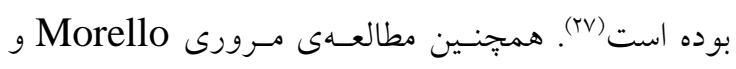

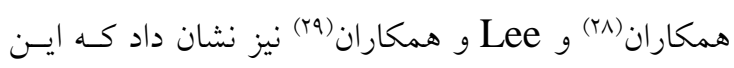
بعد در بيشتر مطالعات در وضعيت خوبى قـرار دارد. ايسن بعـد در مطالعسهى Tavares و همكــاران كـه در مــورد يرستاران يكى بيمارستان آموزشى در برزيل انجـام شـــ بـا

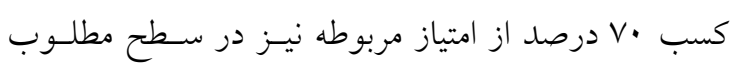

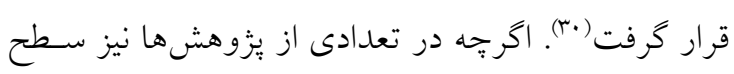

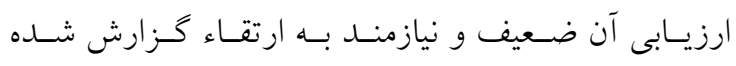

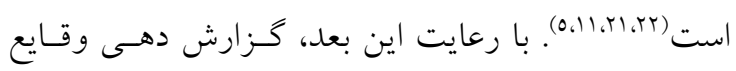
ناخواسته، تبديل به هنجار سازمان مىشود.
در جهت رفع مشكل در سالهاى اخير انجام گرفته است.

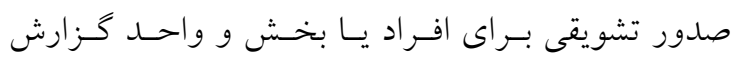
دهنده، از جمله راه كارهايى بود كه بــراى كـاهش تـرس، دغدغه تنبيه و بازخواسـت در بـين كاركنـان انجـام شـده

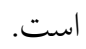
در سال 90"1 و يوسا تعداد كمى از برستاران وضسعيت ايمنى بيمار در واحد خود را بسيار خوب يا عالى گزارش كردند كه با نتـايج مطالعـهى يعقـوبى فــر و همكــاران(r) همخـــوانى دارد. در مطالعـهى Macedo و همكــاران در

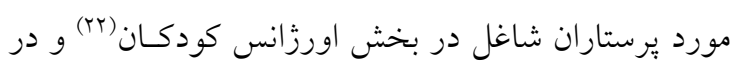
مطالعهى Gunes و همكاران كه در مورد يرستاران شاغل

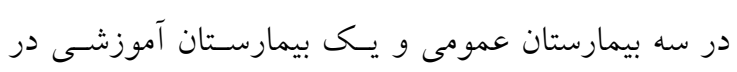

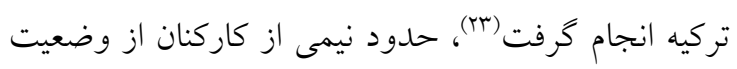
ايمنى بيمار در بخش و واحد خود، رضايت داشتند، كه با نتايج مطالعهى حاضر همخوانى ندارد. به همان نسبت كـه عملكرد و احدها و بخشهاى مختلف بيمارستان در زمينـه ى ايمنى بيمار ارتقاء يافته است، سـطح دانسش و آخـاهى كاركنان نيز در اين زمينه افزايش يافته اسـت. بنـابراين بـا

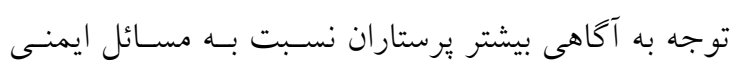

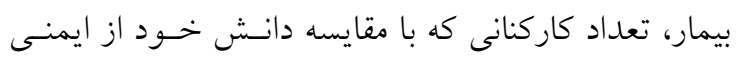

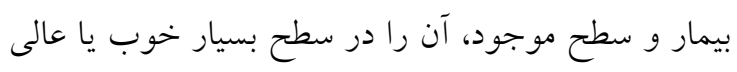

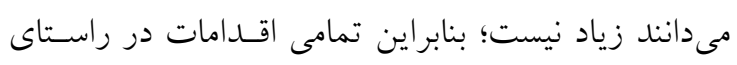

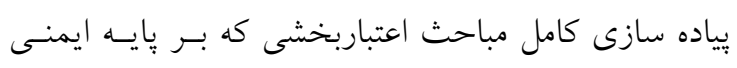
بيمار است، بايستى در بيمارستانها انجام گيرد.

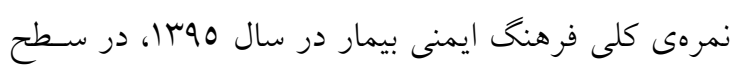
يايين و در سال هوها، در سطح متوسط گزارش شـــ. در همين راستا، نمرهى كلى فرهنخ ايمنى بيمار در مطالعسهى يعقوبى و همكاران در سـال •وبا در سـبزوار در سـطح

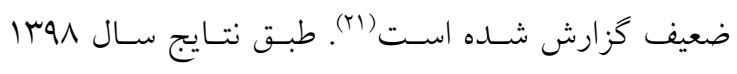
نسبت به سال 90با نمره كلى فرهنگ ايمنى بيمـار رونـد

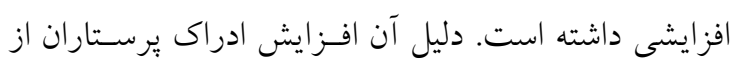

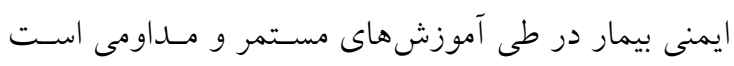

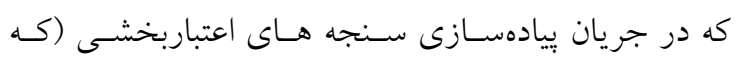

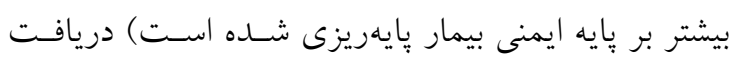


مديريت يرستارى، تحويل و تحول مناسب بيمار در انتقال

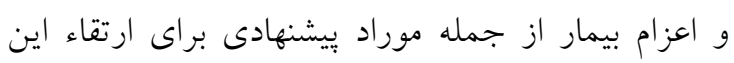
بعد است.

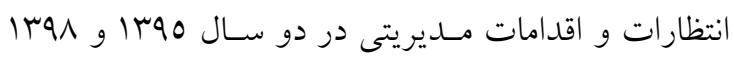

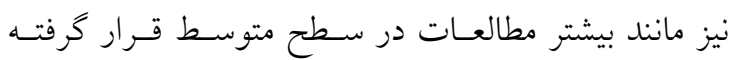

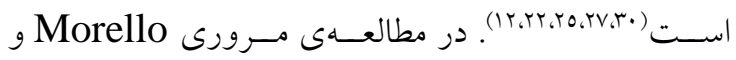

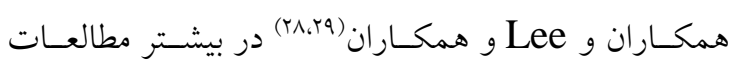
مورد بررسى آنان نمره بالاتر از •V را نشان دادند. مديران

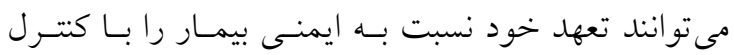

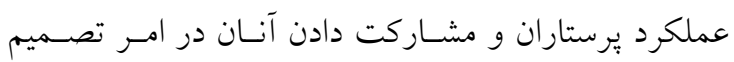
كيرى در مورد امور مربوط به ايمنى بيمار نشان دهند. بعد تناوب كزارشدهى بيانگر آن اسـت كـه هنخـامى كـهـ اشتباهى رخ مىدهد بيش از آنكه بيمار را تحت تأثير قرار

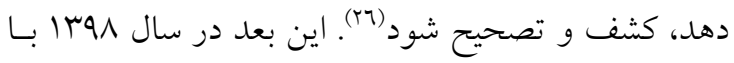
كسب نمره بالاتر از •0 در سطح متوسط قـرار كرفتـه كـهـ

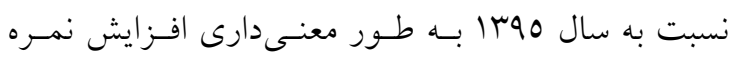
داشته است و با نتايج ساير مطالعات همسو است (1Y.ro.T9).

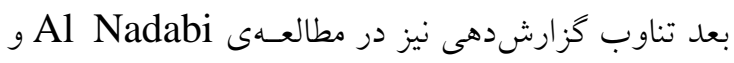

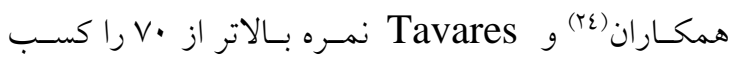

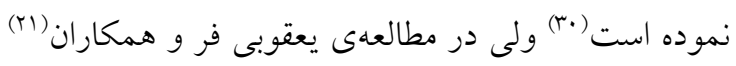

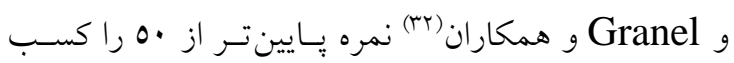

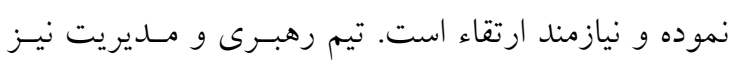

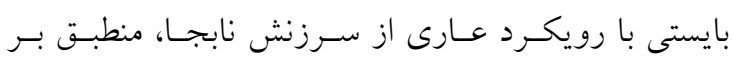

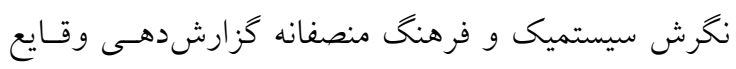
ناخواسته درمان را ترويج نمايند.

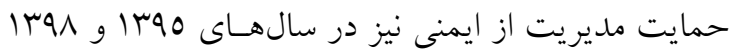
با كسب ميانخين نمره بالاتر از •0 در سطح متوسط دسته دئه

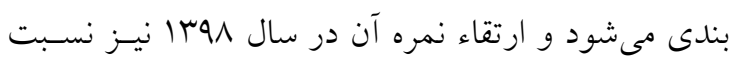

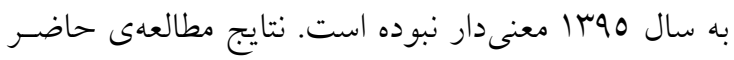

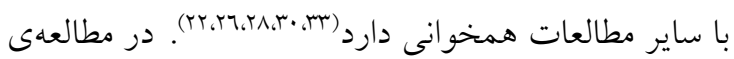
مقرى و همكاران، اين بعد جزء بإيين ترين نمرات از ابعاد

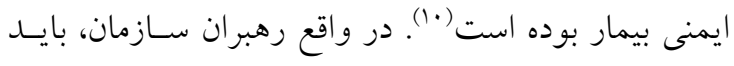

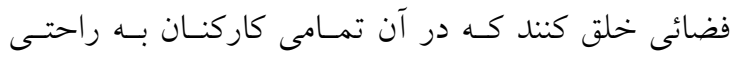

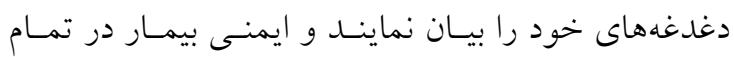

تبادل و انتقال اطلاعات، توانمندى در درك بهتر اطلاعات

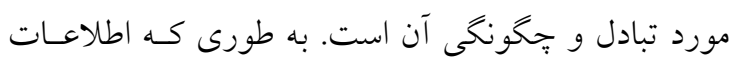

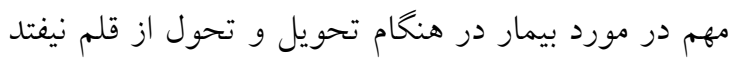

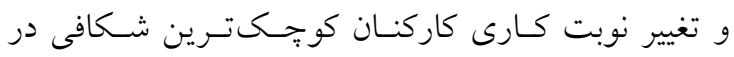

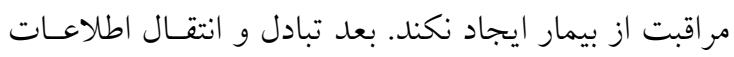

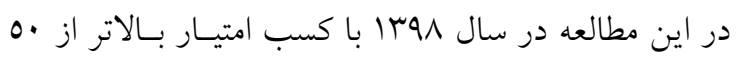

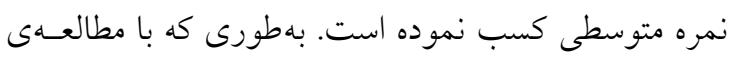

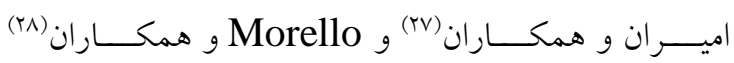
همخوانى دارد. در مطالعهى Wakefield و همكاران كه ومه وماران

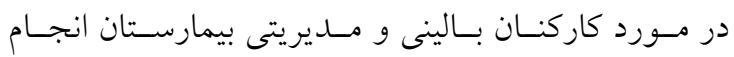

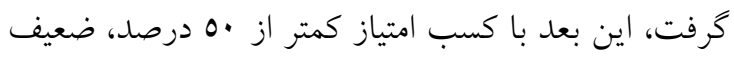

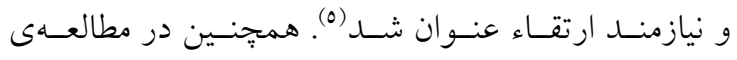
Hessels

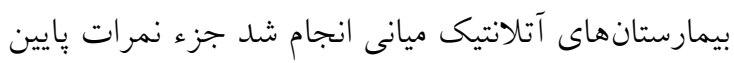

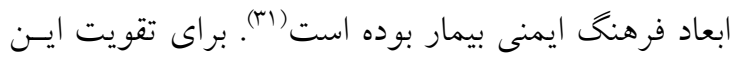
بعد مهم، تسهيل كار تيمى و برورش فرهنگ ايمنى بيمـار

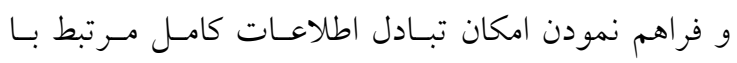

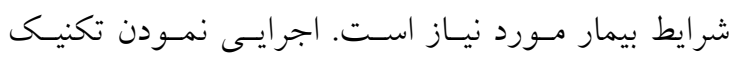
B:Background, A: S:Situation,) SBAR در (Assessment, R: Recommendation بيمارستان در هنگحام تحويل نوبت كـارى و هنخــام انتفـال

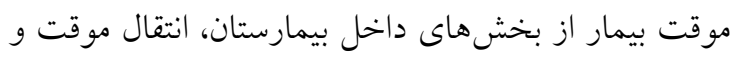

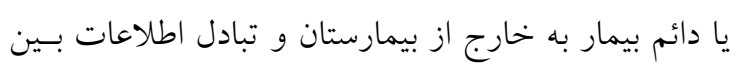

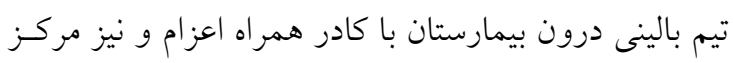
تحويل گيرنده بيمار ضرورى است.

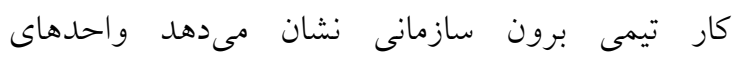

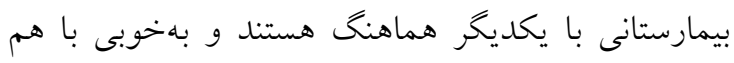

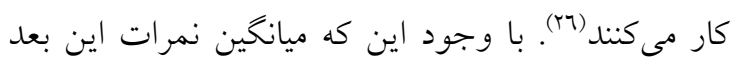

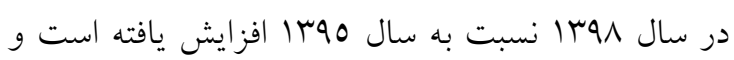

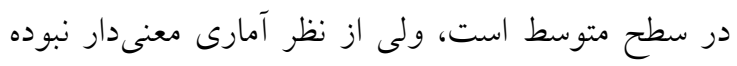

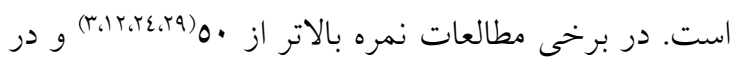

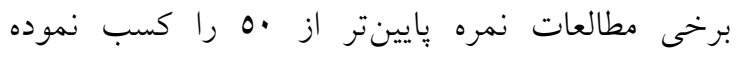

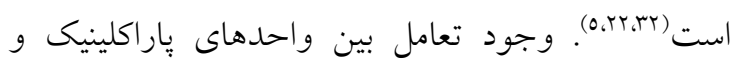

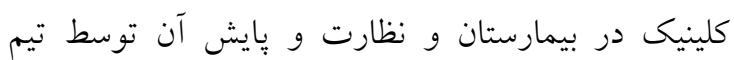


داند كه براى خطاهاى مبتنى بر سيستم تنبيه يـا سـرزنش

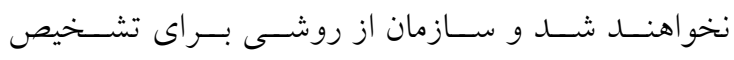

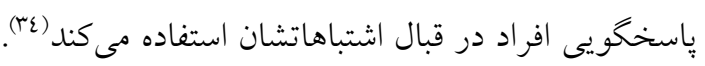
مسائل كاركنان نشان مى دهد كه آنها ساعات طولانى كـار مى كنند و از كاركنان موقت بيش از حد استاندارد، استفاده

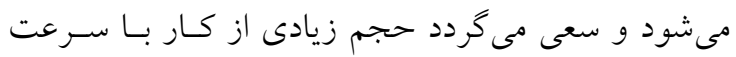

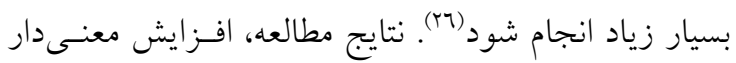

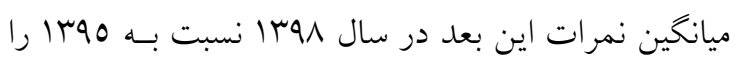

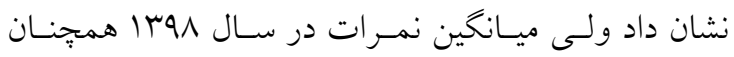
پايينتر از •0 درصد بود. اين بعد در بيشتر مطالعات نمره

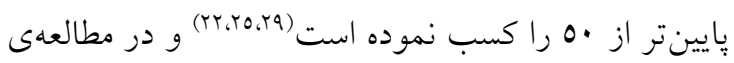
Hessels

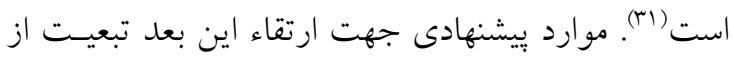

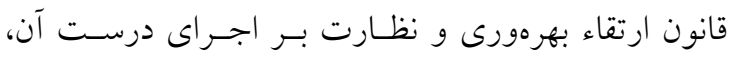

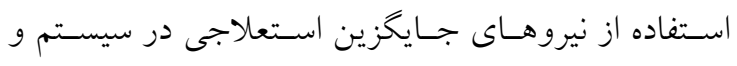

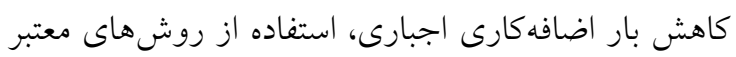
در جينش و ضريب نيرو به تخت، توزيع متوازن نيـرو در

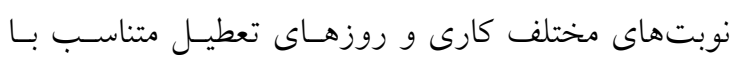
ضريب اشغال تخت بخش است.

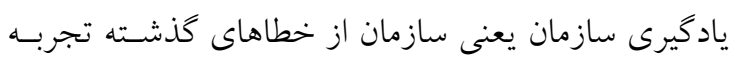

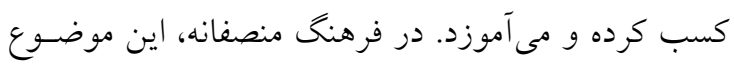

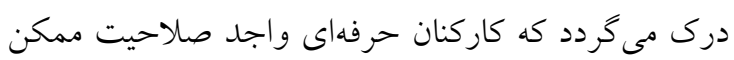

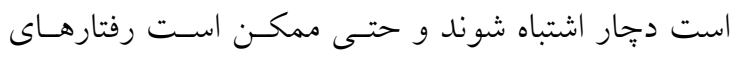

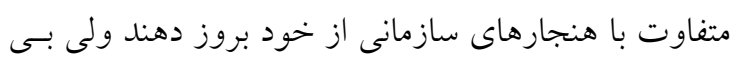

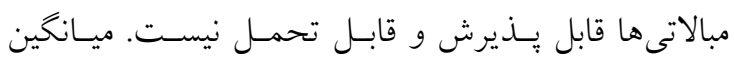

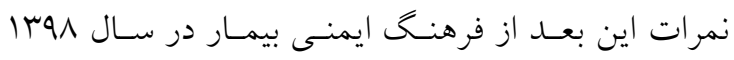

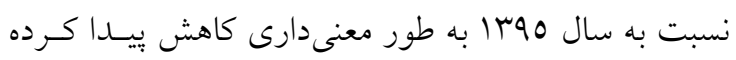

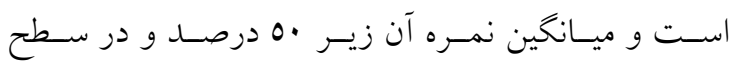
ضعيف دستهبندى مى شود. در برخى مطالعـات ايسن بعـد

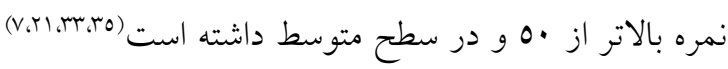

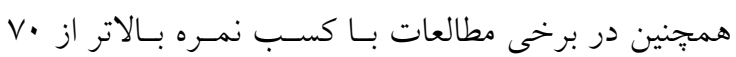

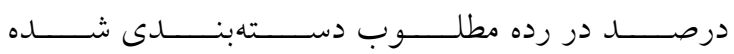

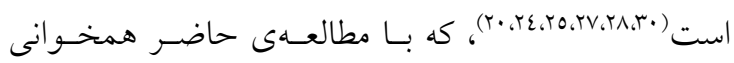
ندارند. در اين مورد به اشتراك كذارى سيستمى خطاهـاى
سـطوح عملكــردى بيمارسـتان بـهـ يــ ارزش سـازمانى نهادينه شده تبديل گردد.

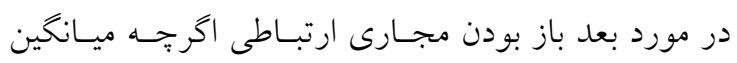

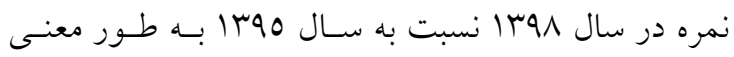

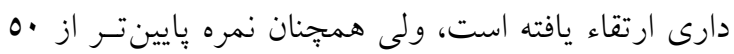
را دارد، كه با مطالعسى

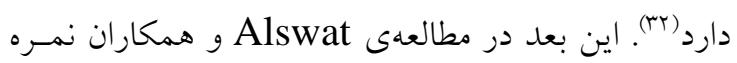

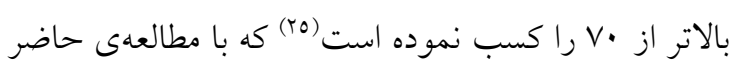

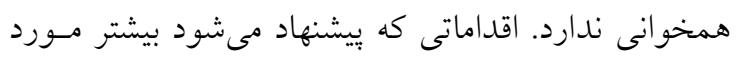

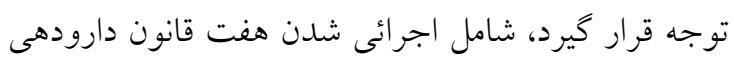
در بيمارستان (قانون هفتم: حق كاركنان در ارتباط با سؤال

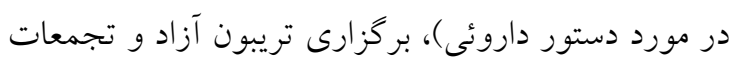

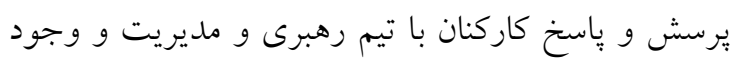

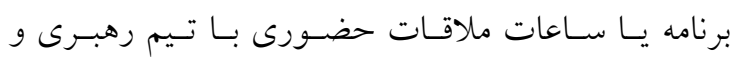

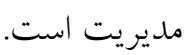
بعد درك كلى از ايمنى نيز در سال هوبا با كسـب نمـره

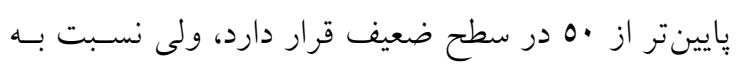
سال 9011 ارتقاء نمره داشته كه از نظـر آمـارى معنسى دار

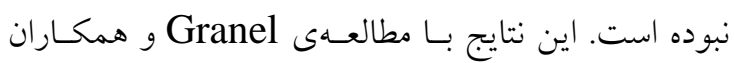

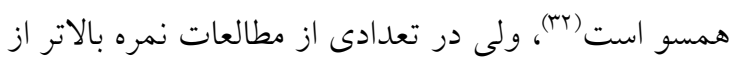

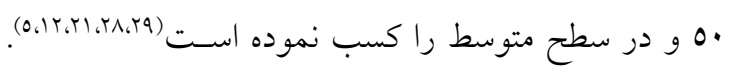

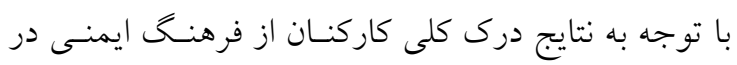

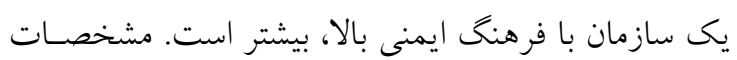

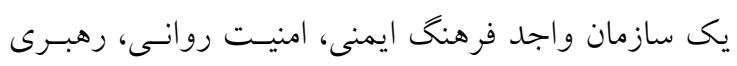

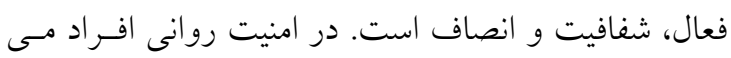

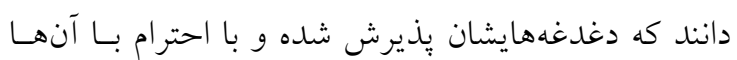

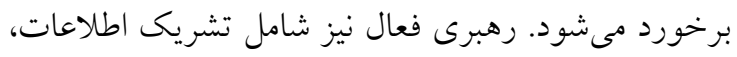
دعوت ساير اعضاى تيم به مشاركت با مهارتها و دغدغنه

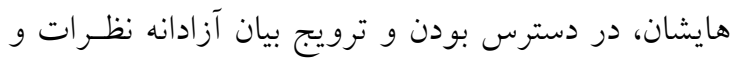
عقايــ Speak Up) اسـتـ شـفافيت، بررسى آسـان خطاهـا، در ميـان كذاشـتن يافتسهــا در درون سـازمان،

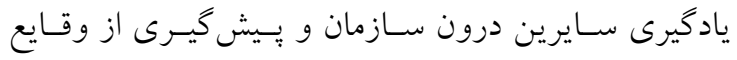

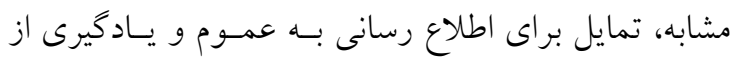

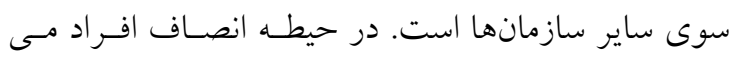




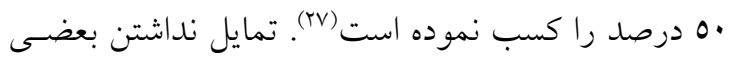

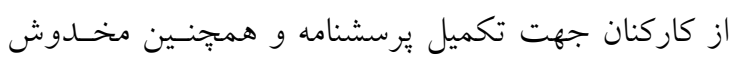

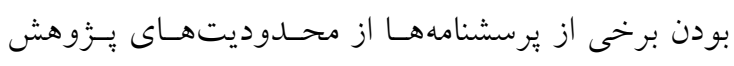

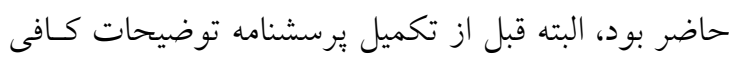

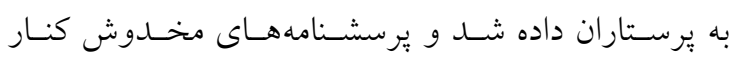
كذاشته و از طرح خارج گرديد.

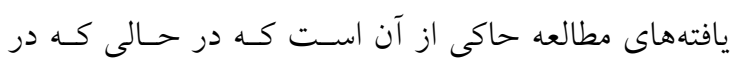

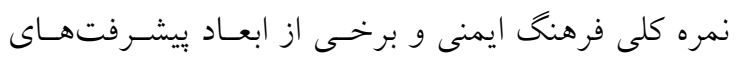

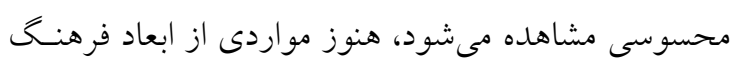

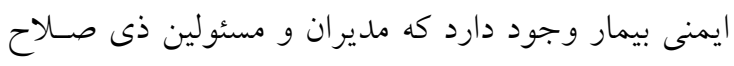

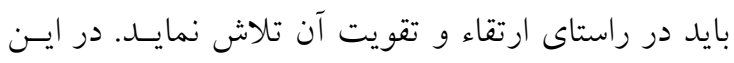

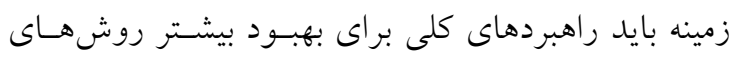

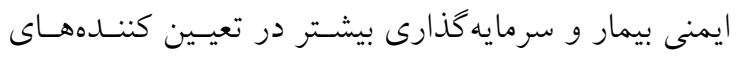

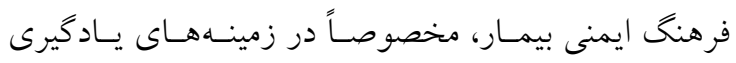

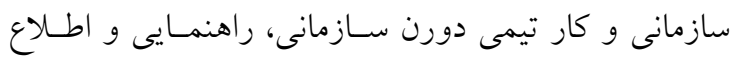
رسانى شود. همجنين ارزيابى و بازديدهاى منظم مديريتى دورنى

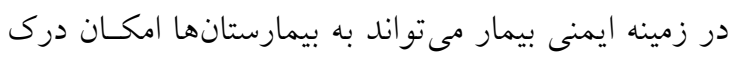

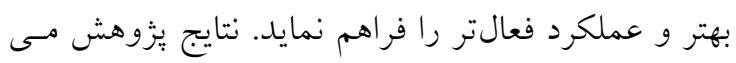

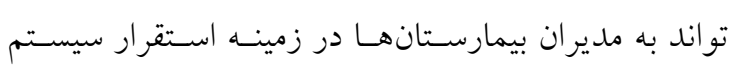

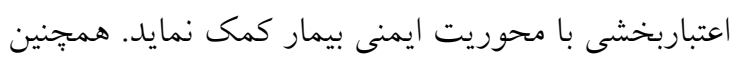

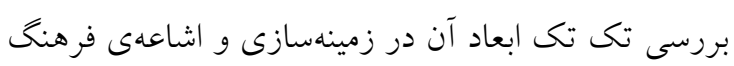

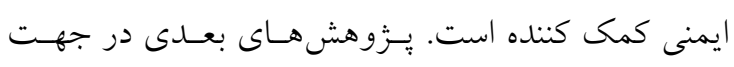

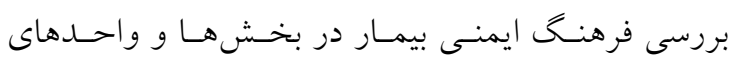

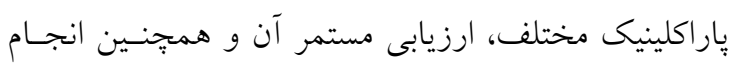
مداخلات اثربخش در جهت تغيير فرهنـ ايمنسى بيمـار توصيه مى گردد.

تضاد منافع: هيجگگ نه تعارض منافع از سـوى نويسـنگان

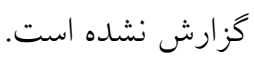

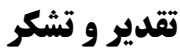

رخ داده شـــه بـه صـورت سـناريو، خبرنامسه و غيـــه در

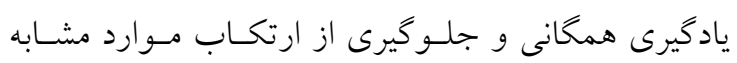

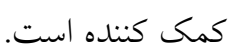
در مورد كار تيمى درون سازمانى، ميانكين نمرات اين بعد الندا

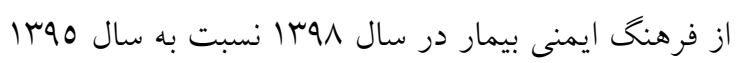

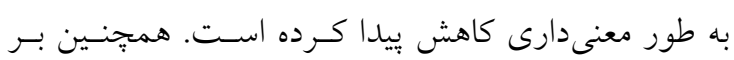

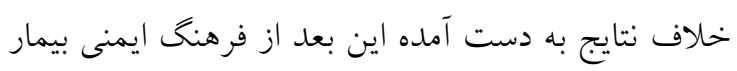

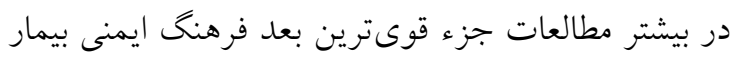

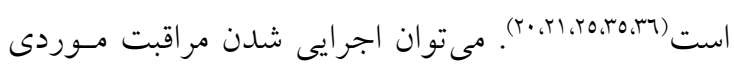

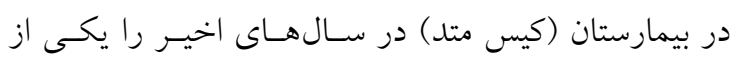
دلايل كاهش ميانخين نمرات اين بعد دانست؛ اخر جـهـ راه

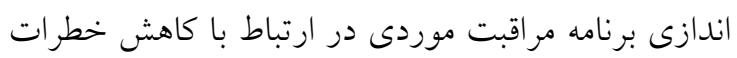

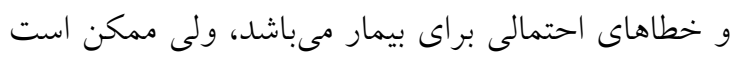

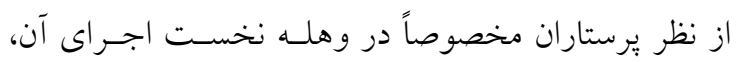
مانعى جهت انجام كار تيمى باشد. توصسيه مسى شـود ايسن

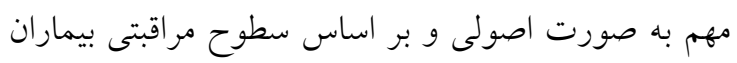

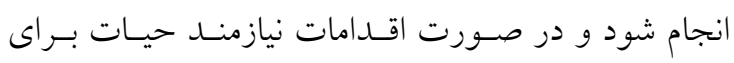

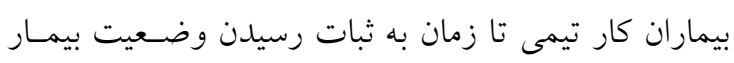

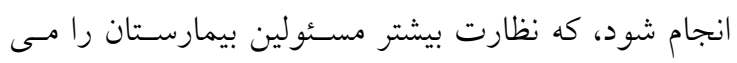
طلبد. - ط در مورد برخورد غيرتنبيهى، فرهنگ ايمنى بيمـار در يـك مانس

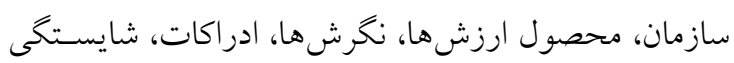

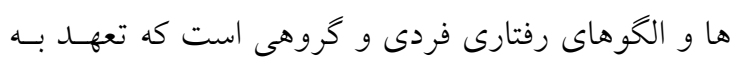

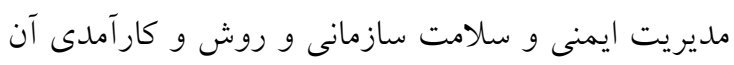

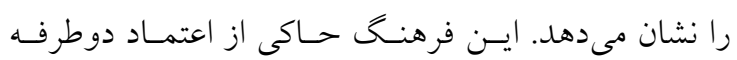

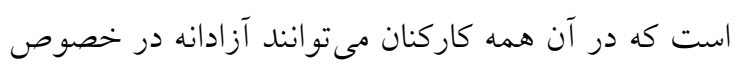

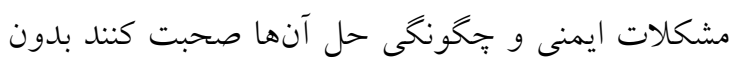
آن كه ترسى از سرزنش غيرمنصفانه يا تنبيه داشته باشـند.

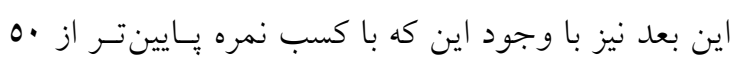

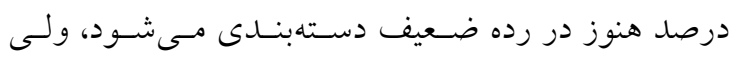

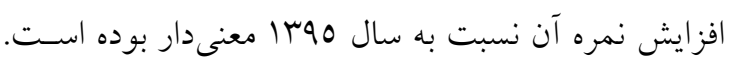
در ساير مطالعات نيز بايينترين نمره را به خود اختصاص

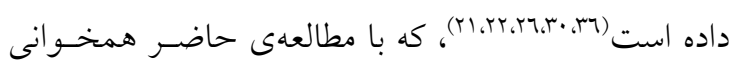
دارد. اين بعد در مطالعهى اميران و همكاران نمره بالاتر از 


$$
\begin{aligned}
& \text { مقاله حاضر حاصل طـرح تحقيقـاتى مصـوب بـا شـماره تحقيقات بالينى بيمارستان واسعى سـبزوار و همجنـين از }
\end{aligned}
$$

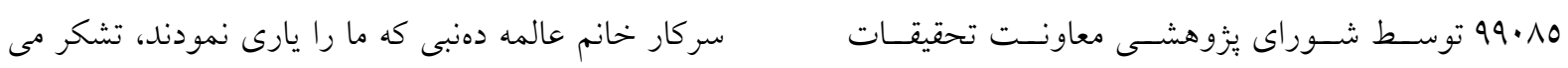

$$
\begin{aligned}
& \text { دانشكاه علوم يزشكى سبزوار است. بدين وسيله از تمامى }
\end{aligned}
$$

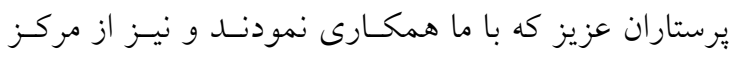

\section{References}

1. Marquis BL, Huston CJ. Leadership roles and management function in nursing. Theory and application. $7^{\text {th }}$ ed. Philadelphia: Lippincott Williams \& Wilkins: 2012; 518.

2. Tahan M, Khakshoor F, Ahangari E. The relationship between teaching patient safety culture with promoting safety culture and self-efficacy of nurses. Journal of Birjand University of Medical Sciences. 2019;26(3):226-36. [Persian]

3. McFadden KL, Stock GN, Gowen III CR. Leadership, safety climate, and continuous quality improvement: impact on process quality and patient safety. Health Care Manag Rev. 2015;40(1):24-34.

4. Weaver SJ, Lubomksi LH, Wilson RF, Pfoh ER, Martinez KA, Dy SM. Promoting a culture of safety as a patient safety strategy: a systematic review. Annals of internal medicine. 2013;158(5_Part_2):369-74.

5. Wakefield JG, McLaws ML, Whitby M, Patton L. Patient safety culture: factors that influence clinician involvement in patient safety behaviours. Quality and Safety in Health Care. 2010;19(6):585-91.

6. Assefa T, Woldie M, Ololo S, Woldemichael K. Patient safety practices and medical errors: Perception of health care providers at Jimma University Specialized Hospital, Southwest Ethiopia.. Open J Prev Med. 2012; 2(2): 162-70.

7. Lopes Campelo C, Alves de Sousa SD, Carvalho Silva LD, Dias RS, Ribeiro Azevedo P, Oliveira Nunes FD, de Souza Paiva S. Patient Safety Culture and the Cultural Nursing Care. Journal of Nursing UFPE/Revista de Enfermagem UFPE. 2018;12(9):2500-6.

8. Shahrabadi R, Moeini B, Roshanai GH, Dashti S, Kafami V, Haghighi M. Assessing Hamadans nurses perceptions of patient safety cultures dimensions. Journal of Hospital. 2014;12(4):83-90. [Persian]

9. Bodur S, Filiz E. A survey on patient safety culture in primary healthcare services in Turkey. Int $J$ Quality Health Care. 2009;21(5):348-55.

10. Moghri J, AKBARI SA, RAHIMI FA, Arab M. Patient safety culture status in general hospitals affiliated to Tehran University of Medical Sciences. Hakim Research Journal. 2013; 16(3): 24350. [Persian]

11. Verbakel NJ, Langelaan M, Verheij TJ, Wagner C, Zwart DL. Effects of patient safety culture interventions on incident reporting in general practice: a cluster randomised trial. Br J Gen Pract. 2015;65(634):e319-29.

12. Reis CT, Paiva SG, Sousa P. The patient safety culture: a systematic review by characteristics of hospital survey on patient safety culture dimensions. Int J Quality Health Care. 2018;30(9):66077.

13. Okuyama JH, Galvao TF, Silva MT. Healthcare professional's perception of patient safety measured by the hospital survey on patient safety culture: a systematic review and meta-analysis. Scien World J. 2018:1-12

14. Cappelen K, Aase K, Storm M, Hetland J, Harris A. Psychometric properties of the nursing home survey on patient safety culture in Norwegian nursing homes. BMC health services research. 2016;16(466):2-12.

15. Galvão TF, Lopes MC, Oliva CC, Araújo ME, Silva MT. Patient safety culture in a university hospital. Revista latino-americana de enfermagem. 2018;26:e3014.

16. Tajabadi A, Ahmadi F, Sadooghi Asl A, Vaismoradi M. Unsafe nursing documentation: A qualitative content analysis. Nursing ethics. 2020;27(5):1213-24. 
17. Hughes CM, Lapane KL. Nurses' and nursing assistants' perceptions of patient safety culture in nursing homes. Int J Qual Health Care. 2006;18(4):281-6.

18. Sonğur C, Özer Ö, Gün Ç, Top M. Patient safety culture, evidence-based practice and performance in nursing. System Pract Act Res. 2018;31(4):359-74.

19. Toso GL, Golle L, Magnago TS, Herr GE, Loro MM, Aozane F, Kolankiewicz AC. Patient safety culture in hospitals within the nursing perspective. Revista gaucha de enfermagem. 2016 15;37.

20. Shahian DM, Liu X, Rossi LP, Mort EA, Normand SL. Safety culture and mortality after acute myocardial infarction: A study of medicare beneficiaries at 171 hospitals. Health Servic Res. 2018;53(2):608-31.

21. Yaghobi FM, Takbiri A, Haghgoshaye E, Tabarraye Y. The survey of patient safety culture and recognizing its weaknesses and strengths in Sabzevar hospitals: 2011. Journal of Sabzevar University of Medical Sciences. 2013;20(2): 154-64. [Persian]

22. Macedo TR, Rocha PK, Tomazoni A, Souza SD, Anders JC, Davis K. The culture of patient safety from the perspective of the pediatric emergency nursing team. Revista da Escola de Enfermagem da USP. 2016;50:756-62.

23. Güneş ÜY, Gürlek Ö, Sönmez M. A survey of the patient safety culture of hospital nurses in Turkey. Collegian. 2016;23(2):225-32.

24. Al Nadabi W, McIntosh B, McClelland T, Mohammed M. Patient safety culture in maternity units: a review. Int J Health Care Quality Assurance. 2019;32(4):662-76.

25. Alswat K, Abdalla RA, Titi MA, Bakash M, Mehmood F, Zubairi B, Jamal D, El-Jardali F. Improving patient safety culture in Saudi Arabia (2012-2015): trending, improvement and benchmarking. BMC Health Services Research. 2017;17(1):1-4.

26. Gunawan D, Hariyati RT. The implementation of patient safety culture in nursing practice. Enfermeria clinica. 2019;29:139-45.

27. Pour RM, Fatemi MA. Evaluation of patient safety culture based on the viewpoint of nurses and physicians employed in a Military hospital. Military Caring Sciences.2018; 5(1). 26-33. [Persian]

28. Morello RT, Lowthian JA, Barker AL, McGinnes R, Dunt D, Brand C. Strategies for improving patient safety culture in hospitals: a systematic review. BMJ quality \& safety. 2013;22(1):11-8.

29. Lee SE, Scott LD, Dahinten VS, Vincent C, Lopez KD, Park CG. Safety culture, patient safety, and quality of care outcomes: a literature review. West J Nurs Res. 2019;41(2):279-304.

30. Tavares AP, Moura EC, Avelino FV, Lopes VC, Nogueira LT. Patient safety culture from the perspective of the nursing team. Rev Rene. 2018;19: 1-7.

31. Hessels A, Paliwal M, Weaver SH, Siddiqui D, Wurmser TA. Impact of patient safety culture on missed nursing care and adverse patient events. J Nurs Care Qual. 2019;34(4):287-94.

32. Granel N, Manresa-Domínguez JM, Barth A, Papp K, Bernabeu-Tamayo MD. Patient safety culture in Hungarian hospitals. Int J Health Care Quality Assur. 2019;32(2):412-24.

33. Fan CJ, Pawlik TM, Daniels T, Vernon N, Banks K, Westby P, Wick EC, Sexton JB, Makary MA. Association of safety culture with surgical site infection outcomes. J Am College Surg. 2016;222(2):122-8.

34. Li Y, Zhao Y, Hao Y, Jiao M, Ma H, Teng B, Yang K, Sun T, Wu Q, Qiao H. Perceptions of patient safety culture among healthcare employees in tertiary hospitals of Heilongjiang province in northern China: a cross-sectional study. Int J Qual i Health Care. 2018;30(8):618-23.

35. Arrieta A, Suárez G, Hakim G. Assessment of patient safety culture in private and public hospitals in Peru. Int J Qual Health Care. 2018;30(3):186-91.

36. Berry JC, Davis JT, Bartman T, Hafer CC, Lieb LM, Khan N, Brilli RJ. Improved safety culture and teamwork climate are associated with decreases in patient harm and hospital mortality across a hospital system. $J$ patient safety. 2020;16(2):130-6. 